Document downloaded from:

http://hdl.handle.net/10251/178643

This paper must be cited as:

Giordano, E.; Bertolesi, E.; Clementi, F.; Buitrago, M.; Adam, JM.; Ivorra Chorro, S. (2021). Unreinforced and TRM-reinforced masonry building subjected to pseudo-dynamic excitations: numerical and experimental insights. Journal of Engineering Mechanics. 147(12):04021107-1-04021107-15. https://doi.org/10.1061/(ASCE)EM.1943-7889.0002017

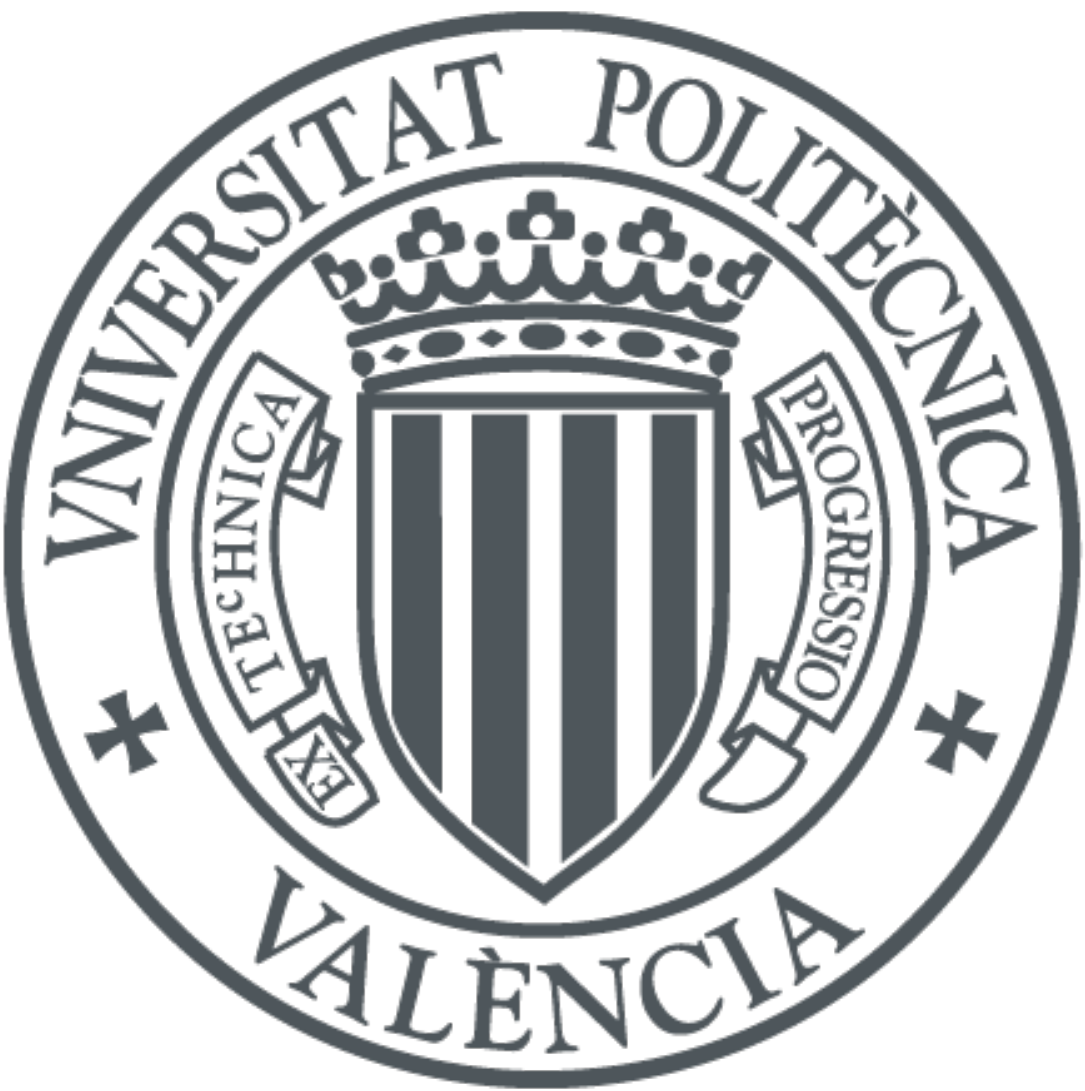

The final publication is available at

https://doi.org/10.1061/(ASCE)EM.1943-7889.0002017

Copyright American Society of Civil Engineers

Additional Information 


\title{
Unreinforced and TRM-reinforced masonry building subjected to pseudo- dynamic excitations: numerical and experimental insights
}

\author{
Ersilia Giordano ${ }^{1}$, Elisa Bertolesi ${ }^{2}$, Francesco Clementi ${ }^{3 *}$, Manuel Buitrago ${ }^{4}$, José \\ M. Adam ${ }^{5}$, Salvador Ivorra ${ }^{6}$ \\ ${ }^{1}$ Ph.D., Department of ICEA, Università Politecnica delle Marche, ,Via Brecce Bianche 12, \\ 60131, Ancona, Italy, e.giordano@pm.univpm.it. \\ ${ }^{2}$ Ph.D., Department of Civil and Environmental Engineering, Brunel University London, UB8 \\ 3PH Uxbridge, UK, elisa.bertolesi@brunel.ac.uk. \\ ${ }^{3}$ Professor, Ph.D., Department of ICEA, Università Politecnica delle Marche,Via Brecce \\ Bianche 12,60131, Ancona, Italy, francesco.clementi@univpm.it. \\ ${ }^{4}$ Ph.D. ICITECH, Universitat Politècnica de València, Camino de Vera s/n, 46022, Valencia, \\ Spain,mabuimo1@upv.es \\ ${ }^{5}$ Professor, Ph.D. ICITECH, Universitat Politècnica de València, Camino de Vera s/n, 46022, \\ Valencia, Spain,joadmar@upv.es. \\ ${ }^{6}$ Professor, Ph.D., Department of Civil Engineering. Universidad de Alicante, Carretera San \\ Vicente s/n,03690 San Vicente del Raspeig, Spain, sivorra@ua.es \\ *Corresponding author: francesco.clementi@univpm.it
}

\section{ABSTRACT}

This paper contains a numerical study based on tests carried out at the Universitat Politècnica de València (Spain) on a U-shaped unreinforced and TRM-reinforced masonry building structure subjected to horizontal loads. The masonry was composed of clay bricks with $10 \mathrm{~mm}$ thick mortar joints arranged in an English bond manner. The prototype was tested by applying pseudo-dynamic displacement-driven cycles and varying cyclic amplitudes and frequencies in two different stages: (i) on the as-built structure and (ii) after the repair and the application of Textile Reinforced Mortar (TRM) material. A series of non-linear numerical simulations were performed adopting the ABAQUS/Explicit FE software. The FE calibration was carried out using the results obtained during ambient vibration tests. Simulations were then used to evaluate the effectiveness of the proposed TRM technique to increasing the strength of low-rise old masonry building structures.

Keywords: masonry; computational modeling; Textile Reinforced Mortar (TRM); building 
A large number of masonry buildings around the world are considered historical architectural assets. The factors that allowed the widespread diffusion of this type of construction are the easy availability of its constituent materials, such as stones, mud, clay, and the simple installation. Although they may appear to be massive structures, some of their features make them prone to severe damage when subjected to horizontal loads, such as those generated by earthquakes (Acito et al. 2014; Clementi et al. 2020; Milani and Valente 2015; Penna et al. 2014; Vlachakis et al. 2020). The vulnerability of these structures is generally due to the combination of various factors, namely: uneven construction, poor quality of the constituent materials and complex geometries. During a seismic event, historical masonry structures tend to behave as an assemblage of macro-elements that respond differently to the horizontal actions (Giuffré 1996). The subdivision into macro-elements is caused by absent or scarce interlocking between floors and walls, openings too close to the corners of the buildings, or excessively slender elements. Given the great artistic and cultural value of these buildings, it is necessary to identify interventions capable of increasing box-like behavior without neglecting the principles of restoration (ICOMOS 1964; De Naeyer et al. 2000) thus preserving their social value.

Over the years, various restoration techniques have been used to improve the buildings' response both at the local and global levels, and the most frequently used of these are: metal chains, concrete or steel curbs, reinforced concrete plaster and Fiber Reinforced Polymer composites (FRP) (Bhattacharya et al. 2014; Milani and Lourenço 2013a; b; Wang et al. 2018). The latter was first introduced during the II World War from aeronautical engineering and began to be used for reinforcements around 1990 (Hollaway 2010). FRP is a composite material comprising an organic matrix and a fiber reinforcement. The reinforcement can be either in the form of laminates or sheets (the most popular are glass, carbon and aramid fibers) which are glued to the structure using polymeric matrices. FRP composites can increase the shear and bending resistance of panels or, if suitably anchored to perpendicular walls, they can be used to prevent out-of-plane overturning mechanisms (Babatunde 2017; Di Tommaso and Focacci 2001). The well-known advantages of FRPs are: (i) lightness, (ii) high tensile strength, (iii) corrosion resistance and (iv) ease of installation. However, this material also has a few disadvantages: 
partial reversibility, slight toxicity and non-permeability (a particularly critical aspect for masonry structures).

To overcome the weaknesses of FRP, alternative strengthening materials have recently been introduced, such as Textile Reinforced Mortars, (TRM) (also known as Fiber Reinforced Concrete Mortar, FRCM) (Papanicolaou et al. 2008). Two features differentiate TRM materials from FRPs: (i) the matrix, which is cementitious rather than polymeric and can work better in a masonry structure, and (ii) the arrangement of fiber bundles in the form of textiles to improve adhesion to the matrix. This strengthening material has further advantages compared to FRP, such as being completely reversible, heat resistant or permeable and applicable to damp surfaces. The intrinsic characteristics of this material influence its predominant failure modes, which are: (i) fiber tensile failure, (ii) sliding of the fiber in the matrix and (iii) detachment from the substrate (American Concrete Institute 2013; Consiglio Superiore dei Lavori Pubblici 2018).

Although the advantages over the FRP seem to be many, the TRM is, to date, little used. The limited use of FRCM is mainly connected to open issues that are still under study. Some of these are: how fibers behave in an alkaline environment, how the strength of the composite changes if cured in non-uniform humidity and temperature conditions, and how the strength of the composite changes over time (Ghiassi 2020). Another consequence is the use of it almost exclusively on masonry structures since for R.C. structures the FRP is preferred since the latter has epoxy resin which guarantees superior performance in terms of displacement and resistance

Even though the use of TRM in practice is still limited, numerous ongoing studies are investigating its durability, compatibility and resistance (Donnini et al. 2016; de Felice et al. 2020; Ghiassi 2020; Grande et al. 2018). There are many studies in the current literature on adhesion and resistance tests on small specimens where the response variation is directly linked to the type of fiber or matrix used (Barducci et al. 2020; Caggegi et al. 2017; Papanicolaou et al. 2008). Fewer studies have been published on largescale tests, such as walls or arches, subjected to in-plane and out-of-plane actions (Bertolesi et al. 2018; Harajli et al. 2010; Ivorra et al. 2021; Sadeghi et al. 2017; Torres et al. 2021) while few tests have been made on scaled buildings (Bertolesi et al. 2020; de Santis et al. 2019). 
This work aims to improve the knowledge on the effectiveness of TRM in strengthening damaged masonry buildings. The authors started from the experimental data obtained from environmental and pseudo-dynamic tests conducted on a 2:3 scale masonry structure (Bertolesi et al. 2020; Bru et al. 2019). The 2:3 scale was chosen with reference to issues of optimizing the use of laboratory space and the position of the actuator. After an initial test, the structure was repaired, reinforced with TRM and retested to check the effectiveness of the strengthening by comparing the capacity curves and the dynamic characteristics of the structure with and without TRM strengthening. The experimental data were treated with the aid of advanced numerical models, with the main purpose of tracking the change of the structural response, considering the effectiveness of the proposed strengthening technique.

The paper is structured as follows. Section 2 briefly describes the material and geometric characteristics of the structure, the tests carried out and the main experimental results. Section 3 describes the Finite Element (FE) model, the calibration carried out with the help of the ambient vibration tests results, the numerical analysis developed and the effectiveness of the TRM strengthening technique. In Section 4 the main conclusions are summarized and discussed.

\section{Experimental Tests}

This section briefly reports the experimental set-up, lab investigation and main results obtained during the experimental campaigns discussed in Bertolesi et al. 2020. The section is structured as follows: (i) description of the specimen and testing procedure, (ii) pseudo-dynamic test results, and (iii) ambient vibration monitoring data results for subsequent $\mathrm{FE}$ calibration.

\subsection{Description of the specimen and testing procedure}

The effectiveness of TRM materials in increasing the strength and ductility of masonry buildings was studied on a 2:3 scale single-story U-shaped structure built in one of the ICITECH laboratories at the Universitat Politècnica de València (Spain).

The structure was constructed using a solid two-headed brick English bond masonry texture. The $0.11 \times 0.05 \times 0.23 \mathrm{~m}^{3}$ bricks were laid with approximately $10 \mathrm{~mm}$ thick layers of lime mortar. The structure 
was designed with a $\mathrm{U}$ configuration with global dimensions of $3.11 \times 4.19 \mathrm{~m}^{2}$ and a height of $2.15 \mathrm{~m}$, with a continuous façade, while the transverse walls had a window and a door, respectively (see Figure 1a). Wooden lintels were positioned over the openings, while the slab was prefabricated and simply supported by reinforced concrete beams and hollow concrete blocks. The structure rested on steel plates anchored to the laboratory floor. These plates had brackets at the corners of the building to prevent sliding (see Figure 1b).
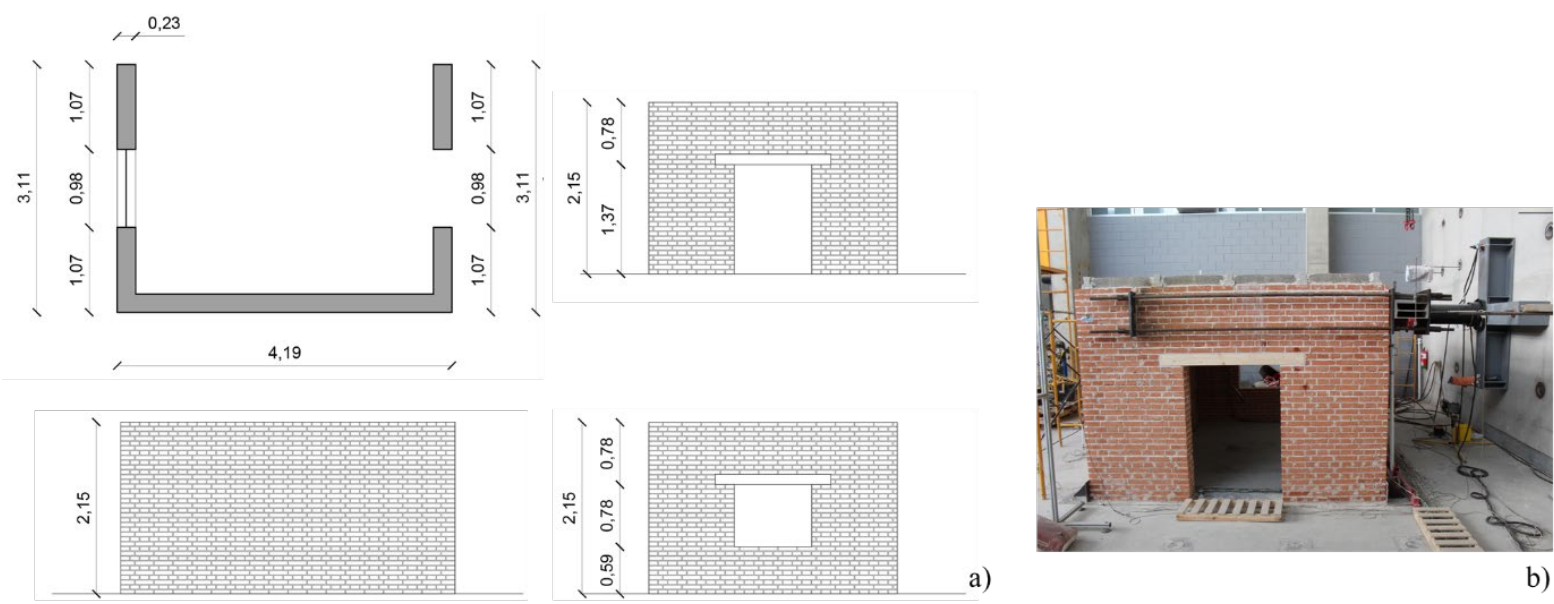

b)

Figure 1. Geometry of the building (a) and setup of the test(b). Dimensions in $\mathrm{m}$.

The mechanical characteristics of the masonry constituent materials, namely bricks and mortar (cured for 28 days, its age on the day of the masonry building test) were obtained by laboratory tests (such as compression and three-point bending tests) and the main values are reported in Table 1.

Table 1. Mechanical parameters of mortar and bricks obtained from experimental tests (COV given in parentheses).

\begin{tabular}{cccc}
\hline & $\mathbf{E}[\mathbf{M P a}]$ & $\boldsymbol{f}_{\mathbf{c}}[\mathbf{M P a}]$ & $\boldsymbol{f}_{\mathbf{f}}[\mathbf{M P a}]$ \\
\hline Clay Brick & $1030(0.21)$ & $14.0(0.14)$ & $4.4(0.19)$ \\
Mortar & $727(0.14)$ & $4.3(0.08)$ & $1.5(1.19)$ \\
\hline
\end{tabular}

After the initial test on the as-built structure, the masonry was repaired by mortar injections to close the cracks and re-establish structural continuity. A layer of TRM consisting of $10 \mathrm{~mm}$ mortar (1.9 $\left.\mathrm{kg} / \mathrm{m}^{3}\right)$ and a bidirectional glass fiber net $\left(225 \mathrm{~g} / \mathrm{m}^{2}\right)$ with mesh dimensions of $25 \times 25 \mathrm{~mm}$ and an equivalent thickness of $0.035 \mathrm{~mm}$ was then applied on the external wall surfaces. The mechanical 
127 parameters of the two components are shown in Table 2 together with the updated values of the 128 strengthening mortar (108 days).

129 Table 2. Material parameters of the fiber (values obtained from the manufacturer) and the matrix of the TRM 130 and the mortar of the masonry building at the day of the second test with the TRM reinforcement (COV given in parentheses).

\begin{tabular}{cccc}
\hline & $\mathbf{E}[\mathbf{M P a}]$ & $\boldsymbol{f}_{\mathbf{t}}$ & $\boldsymbol{f}_{\mathbf{c}}[\mathbf{M P a}]$ \\
\hline TRM-Fiber & 72000 & $45 \mathrm{~N} / \mathrm{mm}$ & - \\
TRM-Matrix & 8000 & $0.8 \mathrm{MPa}$ & 15 \\
Mortar & $1062(0.19)$ & $1.1 \mathrm{MPa}(0.09)$ & $6.0(0.26)$ \\
\hline
\end{tabular}

132

133 After construction, the building was instrumented with 28 Linear Vertical Displacement

134 Transducers (LVDTs), 8 mono-axial accelerometers and 3 fiber-optic sensors to monitor crack

135 propagation and any changes in the structural response as the damage evolved during testing (see Figure

$1362)$. 
Internal view of solid wall

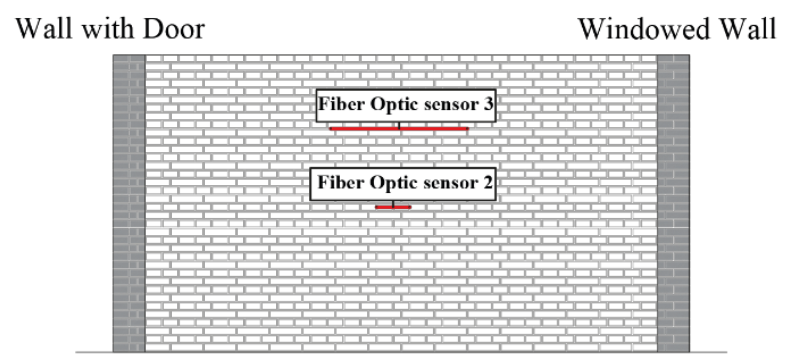

External view of solid wall

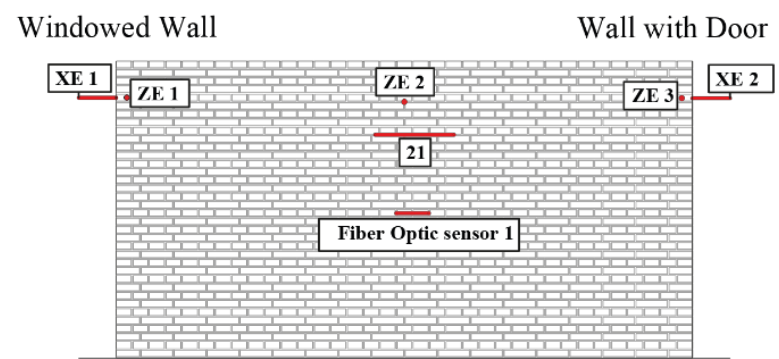

Internal view of windowed wall

Corner

Free Edge

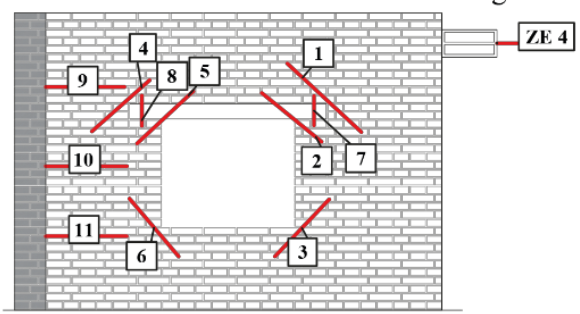

Internal view of wall with door

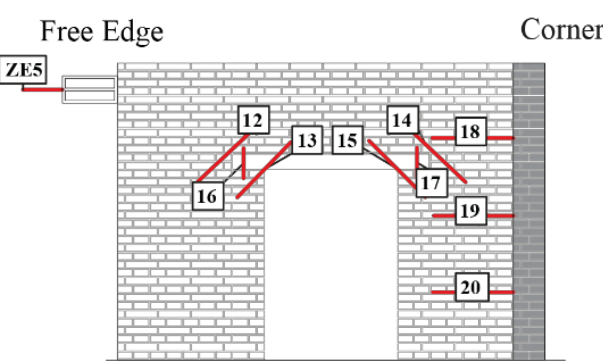

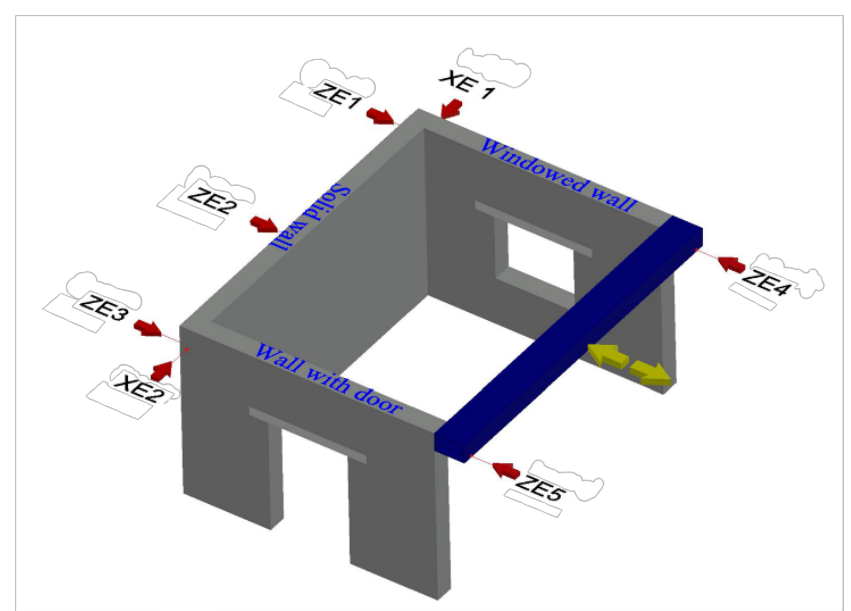

Figure 2. Positions of the 28 LVDTs and the three fiber optic sensors.

Pseudo-dynamic tests were performed in displacement control, with positive and negative displacement cycles of increasing magnitude and frequency, applied through a hydraulic actuator (see Figure 3). The experimental set-up comprised an ad-hoc constructed loading system consisting of steel plates, tie rods and a steel beam. The steel beam, at the center of which the hydraulic jack was fixed (except for the rotation around the vertical axis), was anchored to the top of the transversal walls (see Figure $1 \mathrm{~b}$ and Figure 2) and vertically sustained by four props. 


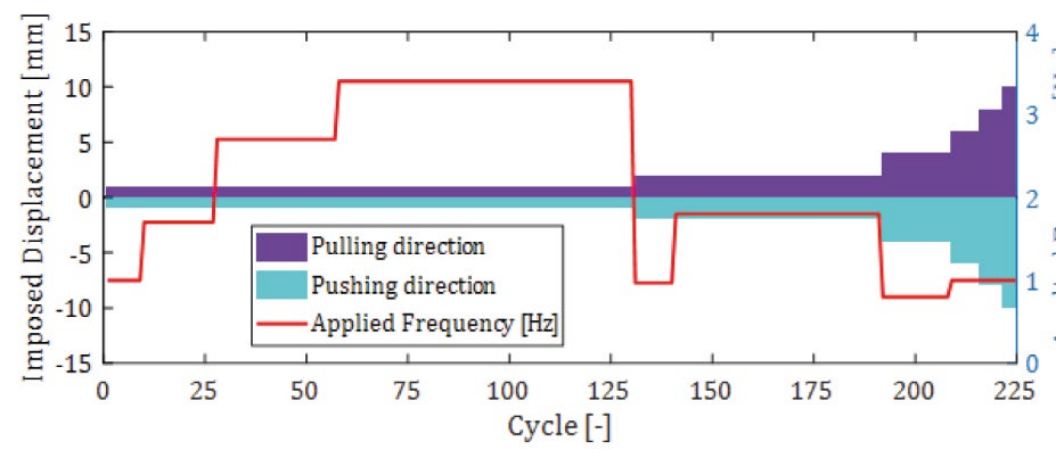

a)

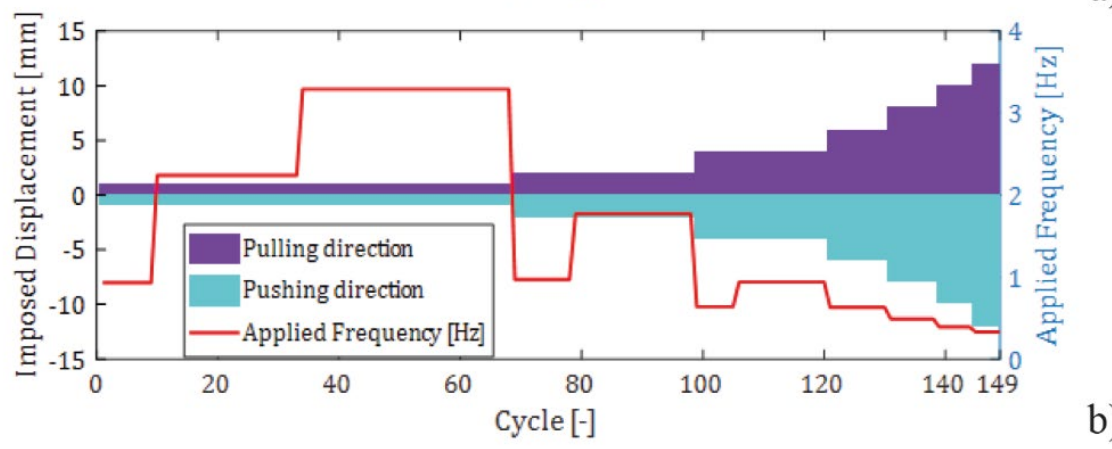

Figure 3. Summary of the dynamic excitations applied to the URM (-a) and TRM-reinforced (-b) structures.

\subsection{Pseudo dynamic tests results}

As stated above, the structure was subjected to pseudo-dynamic tests in displacement control, considering both the unreinforced (URM) and reinforced (RM) stages. During these tests, the reaction forces were recorded with a load cell positioned between the piston of the hydraulic jack and the steel beam while horizontal displacements were tracked with LVDTs (see Figure 2). In this work only the envelopes of the hysteresis loops obtained from the four LVDTs placed on the external corners were used, as they may be seen as representative of the overall behavior of the structure, namely (see Figure 2): ZE1 on the façade in the corner with the windowed wall, ZE3 on the façade in the corner with the wall with the door, ZE4 on the free side in correspondence with the windowed wall, and ZE5 on the free side in correspondence with the wall with the door. Figure 4 contains the hysteresis curves and a summary of these results in the form of envelope curves (in red for the building's pulling action and blue for pushing action), which were obtained considering the maximum force recorded by the load cell in each cycle and the corresponding displacements read by the LVDTs. A more detailed description of these results can be found in (Bertolesi et al. 2020). 


\section{Unreinforced structure}
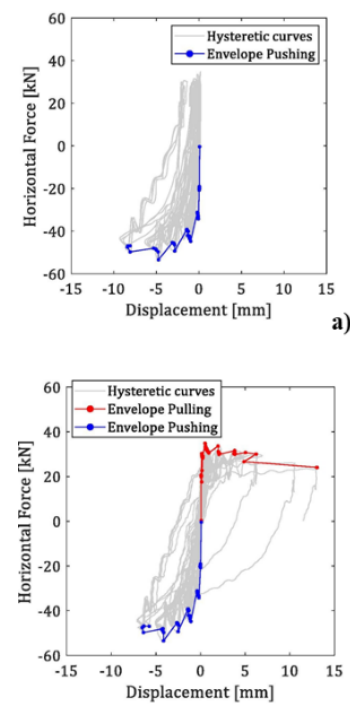

c)

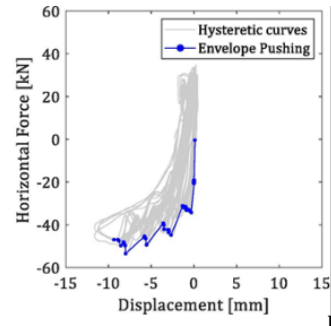

b)

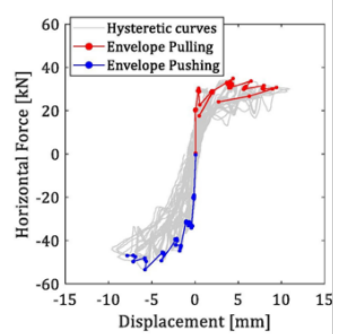

d)

\section{Reinforced structure}
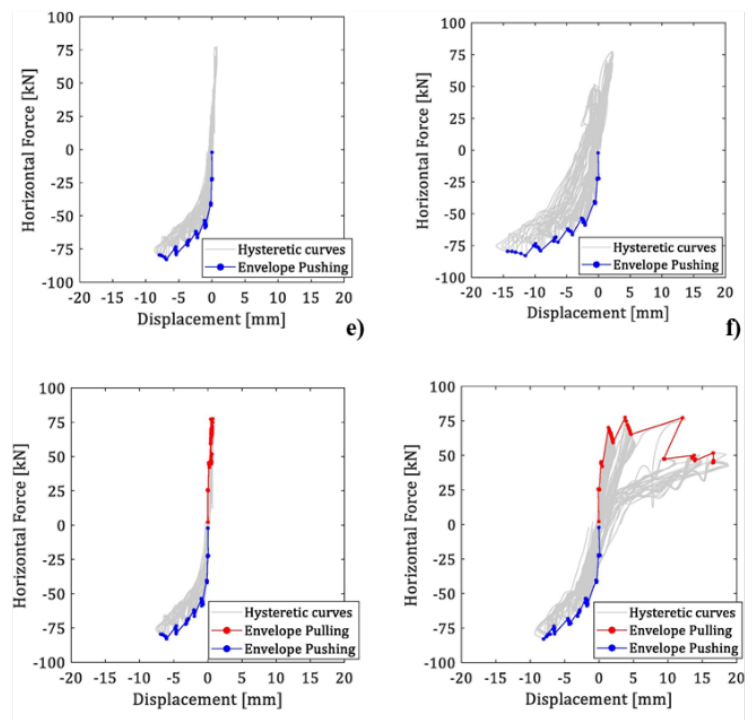

Figure 4. Hysteresis loops and respective envelopes of the unreinforced and reinforced structure considering the LVDTs ZE1 (a,e)-ZE3 (b,f)-ZE4 (c,g)-ZE5 (d,h).

Analyzing the hysteresis curves, it emerged that the URM had a maximum horizontal force of 60 $\mathrm{kN}$, while the application of TRM produced an increase of $30 \%$ in the peak reaction forces. The envelope curves in the pull direction of the LVDTs placed on the façade were not drawn because their trend was strongly influenced by the cracking mechanism. Indeed, after the appearance of the diagonal cracks, which extended from the corners of the openings to the steel plates URM (Figure 5a-b), the facade was no longer involved by the pulling actions.

The damage scenario at the end of the tests is illustrated in Figure 5. Observing the URM (Figure 5a-b), the classic diagonal cracks near the edges of the openings are evident. From the processing of the experimental data, it emerged that the first crack appeared due to a displacement of $2 \mathrm{~mm}$ in the door wall, even if the windowed wall was the element that suffered the most damage at the end of the test. In both cases, the cracks started from the openings and then extended towards the loading system. It should be noted that the structure under large displacements also underwent a detachment of the mortar from the base. Conversely, the TRM-reinforced structure was less damaged at the end of the test (Figure $5 \mathrm{c}-\mathrm{d})$. The door wall showed a small crack in the mortar on the free side and a large crack on the façade side, which formed after an imposed displacement of $4 \mathrm{~mm}$ and the fiber ruptured with a displacement 

produced detachment at the base. Further details are reported in (Bertolesi et al. 2020).

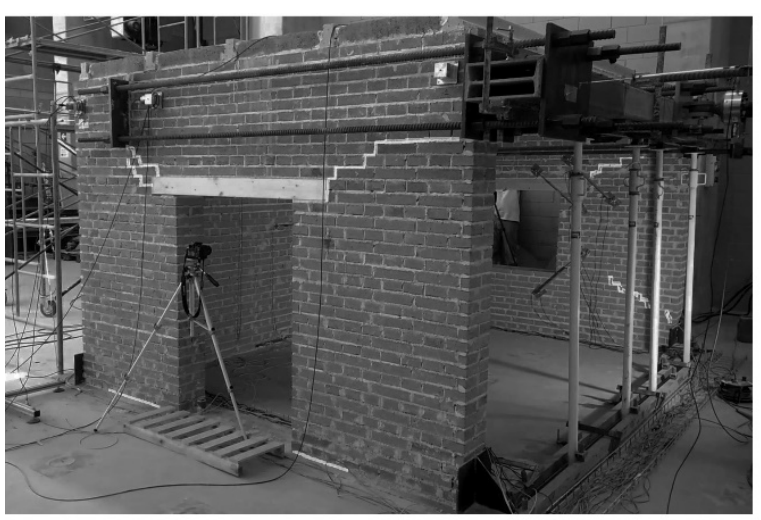

a)
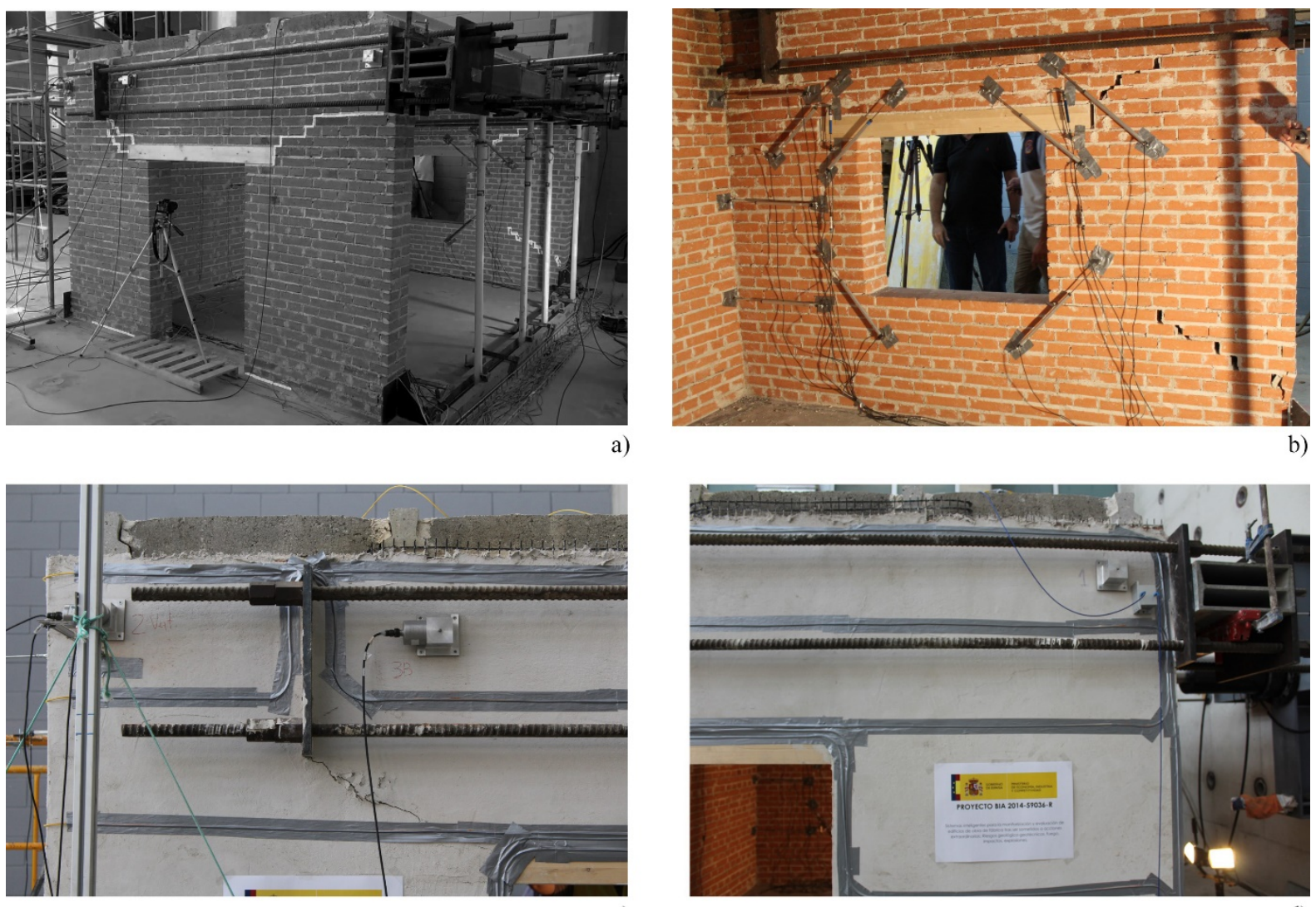

c)

Figure 5. Cracking patterns at the end of the tests for unreinforced (a-b) and reinforced (c-d) structures.

\subsection{Ambient vibration data of the building for a subsequent FE calibration}

In a previous work (Bru et al. 2019), ambient vibration tests were performed to investigate the dynamic characteristics of the structure in different scenarios (i.e. as-built before and after damage, and repaired and reinforced before and after damage) and to evaluate the effects of damages observing the prototype dynamic response. In fact, environmental monitoring is a technique widely used in literature to derive the dynamic parameters of structures and follow their damage (Betti et al. 2015; Masciotta et al. 2014; Mendes et al. 2016; Venanzi et al. 2019). The tests were monitored by eight PCB mono-axial piezoelectric accelerometers (referred to as "An" in Figure 6, where n identifies the number of the sensor). Two 5-minute ambient vibration tests were performed for each scenario at a sampling rate of $1000 \mathrm{~Hz}$, to ensure good resolution of frequencies. The sensor layout is reported in Figure 6, in which the positions were chosen at the points where the greatest displacements were expected. 

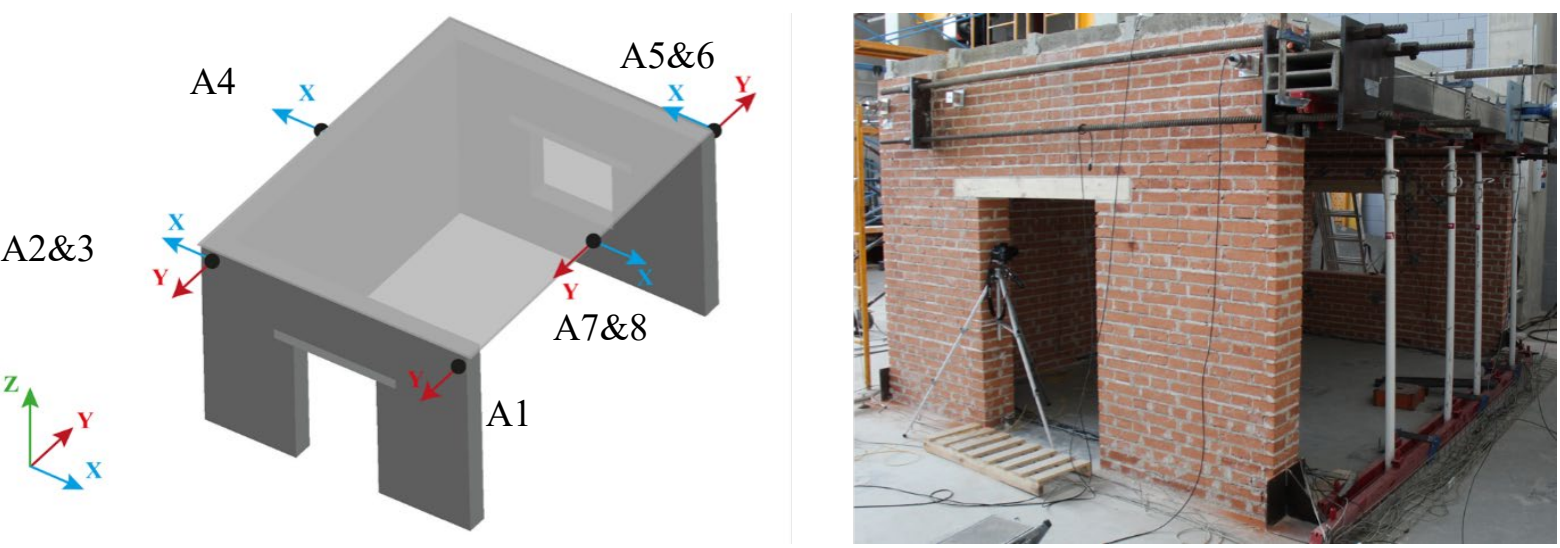

Figure 6. Accelerometric sensors layout.

ARTeMIS (ARTeMIS Modal 2018) software was used to obtain the dynamic parameters. The results extracted from Bru et al. (Bru et al. 2019) were used in the present study to calibrate the subsequent FE model (see Section 3). Table 3 summarizes the frequencies and damping recorded for each configuration, meanwhile Figure 7 shows the modal shapes. Comparing the frequencies there is an average reduction equal to $29 \%$ and $42 \%$ for the URM and TRM reinforced structures attained at the pre-damage and damage scenarios, respectively. This reduction reflects the loss of stiffness due to cracking. The greater variation between frequencies recorded in the TRM structure is associated with the development of a global overturning mechanism, justified by the appearance of horizontal cracks at the base along the perimeter of the structure. Comparing the URM and TRM pre-damage scenarios, it can be seen that the TRM brought about a slight increase in frequencies of about $6 \%$ for the $1^{\text {st }}, 2^{\text {nd }}$ and $4^{\text {th }}$ modes, while a substantial increase of about $26 \%$ was recorded for the $3^{\text {rd }}$ mode.

Table 3. Frequencies and damping of the unreinforced and reinforced structures considering different tests scenarios.

\begin{tabular}{c|cccccccc}
\hline Structures & \multicolumn{3}{|c}{ Unreinforced structure } & \multicolumn{3}{c}{ TRM Reinforced structure } \\
\hline Scenarios & \multicolumn{2}{|c}{ Pre-damage } & \multicolumn{2}{c}{ Post-damage } & \multicolumn{2}{c}{ Pre-damage } & \multicolumn{2}{c}{ Post-damage } \\
\hline Results & Freq. & Damping & Freq. & Damping & Freq. & Damping & Freq. & Damping \\
& {$[\mathrm{Hz}]$} & {$[\%]$} & {$[\mathrm{Hz}]$} & {$[\%]$} & {$[\mathrm{Hz}]$} & {$[\%]$} & {$[\mathrm{Hz}]$} & {$[\%]$} \\
\hline $1^{\text {st }}$ mode & 13.728 & 2.41 & 10.375 & 4.26 & 14.461 & 1.23 & 9.613 & 3.32 \\
$2^{\text {nd }}$ mode & 22.539 & 1.53 & 16.507 & 3.46 & 24.517 & 1.51 & 15.854 & 2.35 \\
$3^{\text {rd }}$ mode & 38.507 & 0.74 & 25.636 & 2.19 & 48.647 & 0.35 & 24.429 & 1.39 \\
$4^{\text {th }}$ mode & 65.097 & 0.50 & 45.445 & 0.86 & 68.517 & 0.69 & 35.210 & 1.16 \\
\hline
\end{tabular}




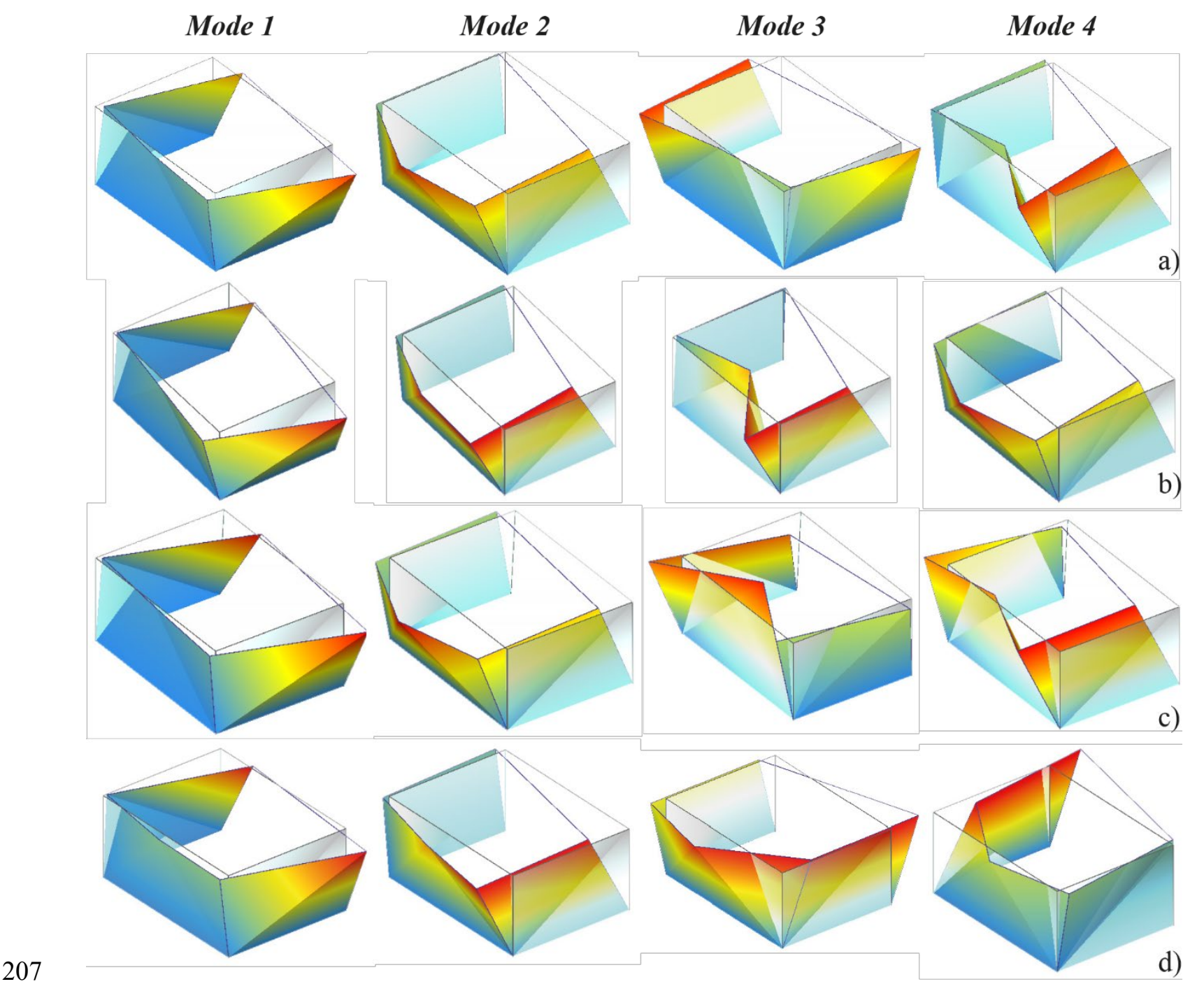

Figure 7. Modal shapes of the URM undamaged (-a), URM damaged (-b), RM undamaged (-c) and RM damaged $(-d)$ structures.

\section{Numerical analysis}

211 To further investigate the influence of TRM strengthening materials on undamaged and damaged

212 low-rise masonry buildings, a non-linear micro-modelling FE model was developed by separately

213 simulating bricks and mortar joints using shell FEs. This section describes the FE model, the calibration

214 carried out with the help of the ambient vibration results and the quasi-static nonlinear analyses

215 performed to study the response of the masonry prototype. 
217 A numerical model accounting for the English bond masonry texture used to build the reference 218 prototype and assuming all the non-linearities lumped in the mortar joints was created using the commercial software package ABAQUS/Explicit (SIMULA ABAQUS 2014). The geometry of the masonry constituent materials, lintels, plates and steel beam was carefully reproduced and subsequently discretized with four-nodes shell elements. In total, the URM model featured 80176 elements and 80774 nodes (see Figure 8-a). The TRM reinforced model was created starting from the URM one adding the TRM strengthening material using skin elements perfectly bonded to the masonry support (see Figure 8-b). In turn, the glass textile embedded into the TRM matrix was taken into account as a reinforcing layer considering the geometrical and mechanical parameters declared by the manufacturer and briefly reported in Section 2. Separate mortar and matrix modeling was chosen following some examples in the literature (de Carvalho Bello et al. 2017; Monaco et al. 2020; Oliveira et al. 2019; Ricci et al. 2018). In the modeling, a perfect bond was considered between mortar and matrix and between TRM and masonry (Garofano et al. 2016; Wang et al. 2017). The one-way roof slab was considered as a superimposed additional mass that discharges $95 \%$ of the weight on the side walls and $5 \%$ on the façade wall. The adopted boundary conditions reflected those observed in the real building. In detail, fixed restraints were used along the entire perimeter of the unreinforced and TRM strengthened masonry building connecting the structure to the ground. The FE model was also provided with a no tension cohesive interface placed between the masonry structure and the reaction floor. The interface was supposed to behave elastically in compression (assuming an Elastic Modulus equal to that of the mortar material) and it was equipped with an elastic perfectly plastic behavior in tension. Wood lintels were considered elastic throughout the study with an elastic modulus of $15 \mathrm{GPa}$, Poisson's ratio equal to 0.3 , and a density of $380 \mathrm{~kg} / \mathrm{m}^{3}$. Similarly, the steel beam composing the loading system was considered elastic with an elastic modulus of $210 \mathrm{GPa}$, Poisson's ratio equal to 0.3 , and a density of $7850 \mathrm{~kg} / \mathrm{m}^{3}$.

240 The mechanical parameters of the masonry constituent materials were taken from laboratory tests on the individual components (see Table 1 (Bertolesi et al. 2020)). Two parameters were calibrated, namely the Elastic Modulus of bricks $(\mathrm{Eb}=8000 \mathrm{MPa})$ and the mortar tensile strength $(\mathrm{ft}=0.11 \mathrm{MPa})$. All the 
other mechanical parameters were assumed as those obtained during laboratory investigations. The

244 brick/mortar densities were taken to be $1656 \mathrm{~kg} / \mathrm{m}^{3}$. The masonry nonlinear behavior was reproduced 245 using the Concrete Damage Plasticity (CDP) model already available in Abaqus in compression and 246 tension for the mortar joints (Figure 9-a), and the TRM matrix (Figure 9-b). The damage was separately 247 assigned to both compressive and tensile behaviors (the maximum allowed damage in both cases was 248 0.9). The mechanical response of the TRM glass textile was also simulated using the CDP material model, namely an elastic perfectly plastic behavior was assumed in tension (E_glass=72 GPa and ft_glass=1276 MPa), while in compression the effect of the glass textile was supposed to be negligible, and the compressive behavior was ruled by the TRM mortar matrix.
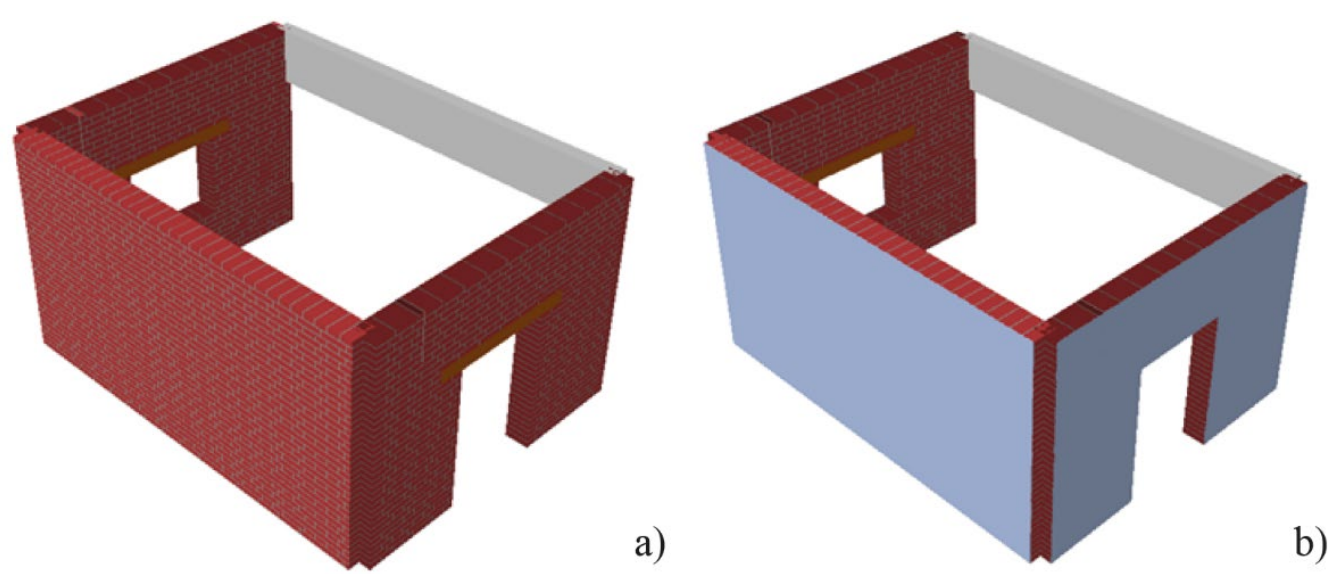

Figure 8. Numerical model for URM (-a) and TRM reinforced (-b) structures.
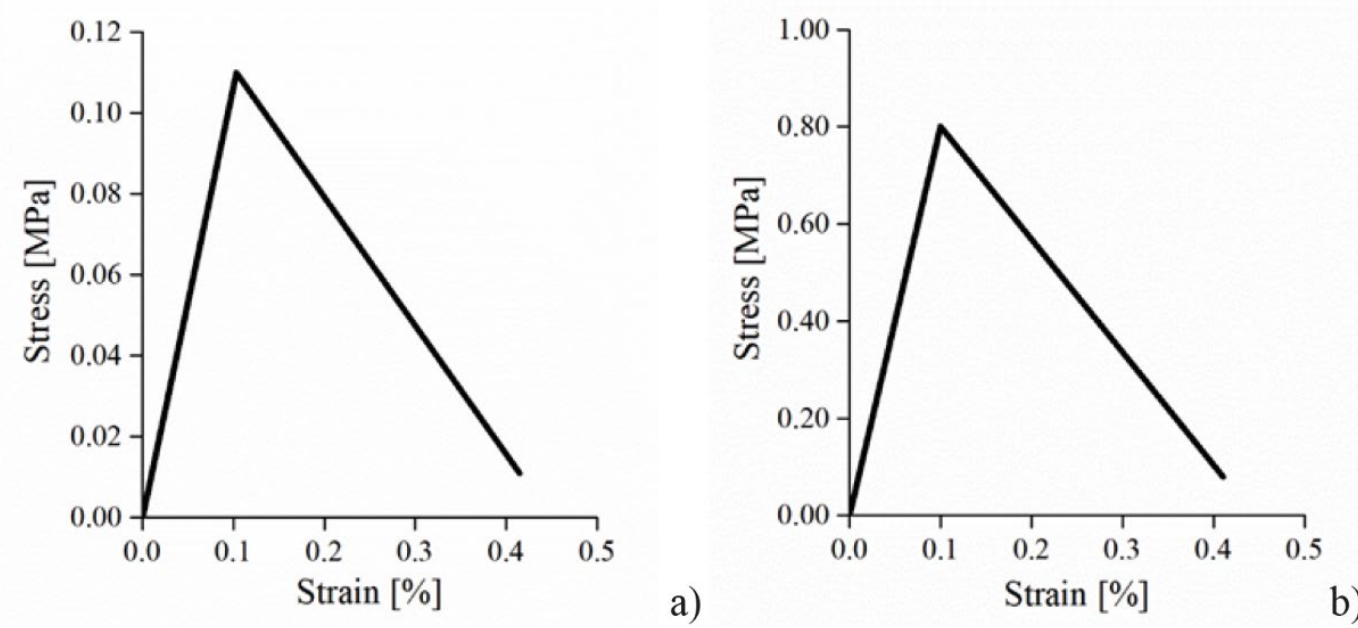

Figure 9. Nonlinear constitutive laws in tension assigned to mortar (-a) and to TRM matrix (-b). 
Due to difficulties to find the convergence of a solution with implicit calculation procedures, the analyses were conducted using an explicit integration scheme with nodal velocities prescribed at the mid-section of the steel beam composing the loading system to reproduce the quasi-static experimental test. The kinetic energy was monitored during the analyses to keep under control those undesirable dynamic effects, and it remained confined to a few parts per thousand of the overall strain energy during the whole test simulation. The time integration step adopted was one million of the whole loading applied, in terms of final displacement applied to the steel beam. Preliminary attempts were performed by the authors until stabilisation of the macroscopic response was observed. A powerful cluster with 512GB RAM and 61 cores working in parallel was used for solving these models, with a time spent around two days for each of the processed models.

\subsection{Calibration of the linear parameters}

The elastic parameters of the masonry constituent materials were calibrated so that the numerical frequencies and the modal shapes were as close as possible to those recorded during dynamic monitoring. To verify the correspondence of the dynamic behavior of the numerical models compared to the tested building, the percentage of frequencies error Eq. (1) $\left(f_{e}\right.$ are the experimental frequencies and $f_{n}$ are the numerical frequencies) and the Modal Assurance Criteria (MAC) between the modal vectors were used.

$$
\Delta f=\left|\frac{f_{e}-f_{n}}{f_{e}}\right| * 100
$$

The MAC was performed by comparing the modal vectors of the numerical model $\left(\psi_{n}\right)$ with the modal vectors recorded during the $\operatorname{OMA}\left(\psi_{e}\right)$, considering all the $i$-th locations of the sensors and the directions. The MAC may assume values between one and zero, with one indicating the perfect correlation while 0 meaning that the modal shapes are completely different Eq. (2).

$$
\operatorname{MAC}(n, e)=\frac{\left|\sum_{j=1}^{3 i}\left(\psi_{e}\right)_{j} *\left(\psi_{n}\right)_{j}^{*}\right|^{2}}{\left(\sum_{j=1}^{3 i}\left(\psi_{e}\right)_{j} *\left(\psi_{e}\right)_{j}^{*}\right) *\left(\sum_{j=1}^{3 i}\left(\psi_{n}\right)_{j} *\left(\psi_{n}\right)_{j}^{*}\right)}
$$



strengthened models employed the mechanical parameters obtained in the laboratory (Table 1 and 276 Section 3.1). Both models showed similar modal shapes, but lower frequencies compared to the data of 277 the dynamic monitoring. (Section 2.3-Figure 10)
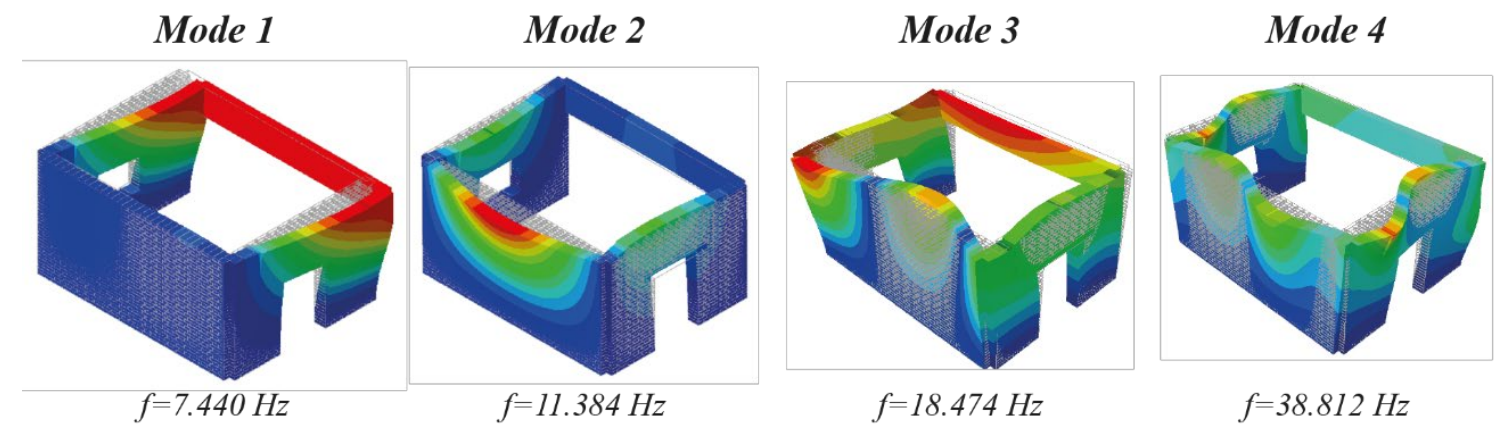

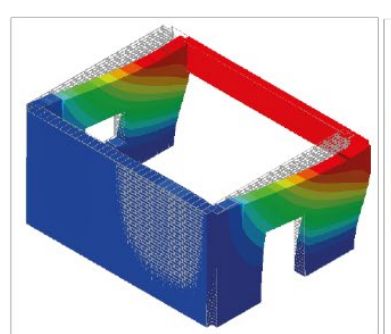

$f=9.453 \mathrm{~Hz}$

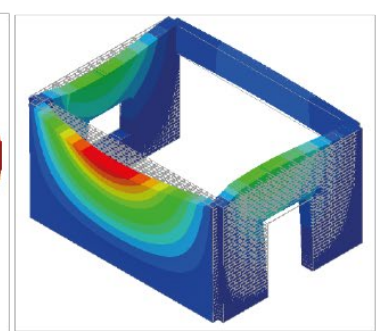

$f=14.228 \mathrm{~Hz}$

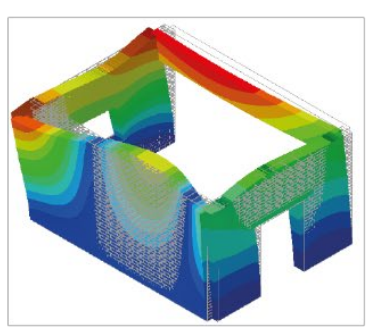

$f=30.774 \mathrm{~Hz}$

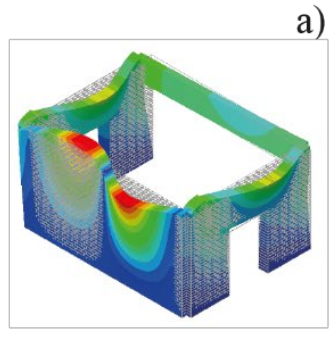

$f=38.693 \mathrm{~Hz}$

a)

Figure 10. Numerical modal shapes and frequencies of the URM (-a) and TRM strengthened (-b) structure with mechanical parameters from Section 3.1.

278 The real structures appeared stiffer compared to the numerical models. To match the frequencies only the Elastic modulus of bricks was updated to $8000 \mathrm{MPa}$. This variation allowed to match the real frequencies of both the models.

Figure 11 shows the comparison between the experimental and numerical modal shapes and frequencies. The MAC values, over $60 \%$, and the frequencies errors, less than $5 \%$ for all the modes, suggest a good reproduction of the real dynamic characteristics of the structure. 
Mode 1

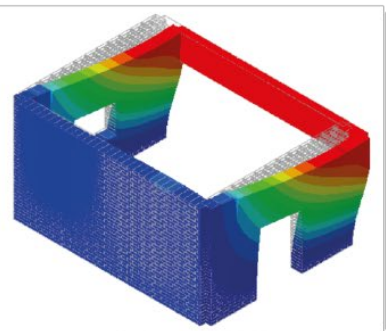

$f=13.534 \mathrm{~Hz}$

$\Delta f=1 \%$

MAC $=\mathbf{8 8 \%}$

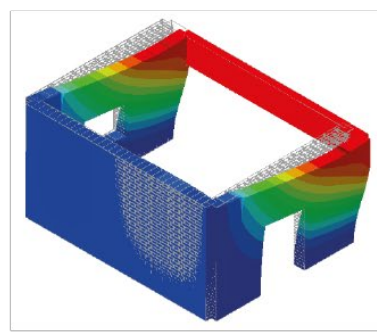

$f=14.902 \mathrm{~Hz}$

$\Delta f=3 \%$

MAC $=98 \%$
Mode 2

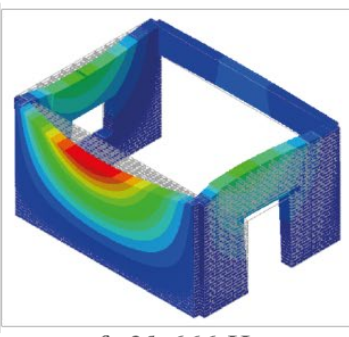

$f=21.666 \mathrm{~Hz}$

\begin{abstract}
$\Delta f=4 \%$
\end{abstract}
MAC $=76 \%$

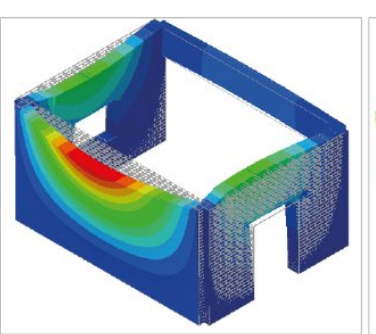

$f=24.103 \mathrm{~Hz}$

$\Delta f=\mathbf{2} \%$

MAC $=77 \%$
Mode 3

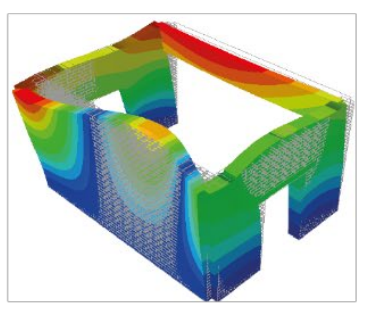

$f=36.765 \mathrm{~Hz}$

$\Delta f=5 \%$

MAC $=\mathbf{8 0} \%$

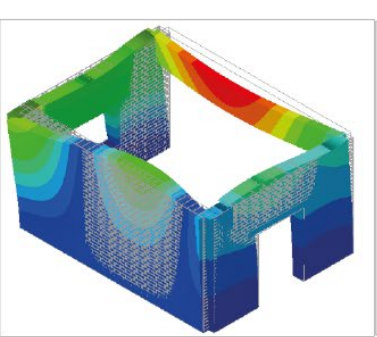

$f=50.792 \mathrm{~Hz}$

$\Delta f=4 \%$

MAC $=92 \%$
Mode 4

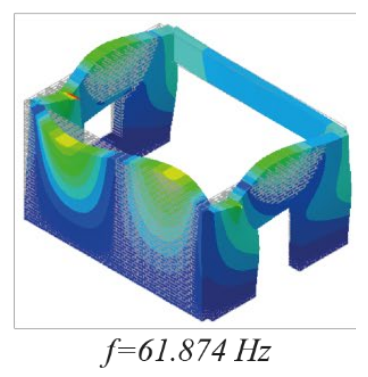

$\Delta f=5 \%$ MAC $=60 \%$

a)

Figure 11. Numerical modal shapes and frequencies of the URM (-a) and TRM strengthened (-b) structure with mechanical parameters update.

\subsection{FE model results and discussion}

\subsubsection{As-built masonry structure}

Following the identification of the main dynamic characteristics of the structure subjected to horizontal actions and repaired with TRM strengthening materials, a series of FE analyses were conducted to: (i) analyze the structural response of the masonry building experimentally tested without and with TRM strengthening, and (ii) evaluate the effectiveness of the adopted TRM strengthening technique.

The FE analyses were carried out by considering both gravity ( $1^{\text {st }}$ phase $)$ and imposed horizontal displacements $\left(2^{\text {nd }}\right.$ phase) until failure. The effect of the jack connected to the steel beam during the second phase was modelled in the FE model by locking the translational and rotational degrees of freedom (DOF) of the nodes in the middle of the steel beam (except for the rotation around the vertical 
axis). At this point, the maximum displacements imposed during the tests were then assigned and increased monotonously.

The first analysis was performed to analyse the structural response of the unreinforced masonry building. The capacity curves were extracted as in the experimental tests, considering the horizontal reaction of the nodes representing the jack and the displacements of the control points taken in the positions of LVDTs ZE1-ZE3-ZE4-ZE5, considering only the push direction.

Figure 12 shows the curves (in blue) obtained at the end of the simulation. As clearly visible, the FE model is able to accurately reproduce the initial elastic phase, peak load and post-peak behavior captured by all the four LVDTs placed on the masonry prototype.
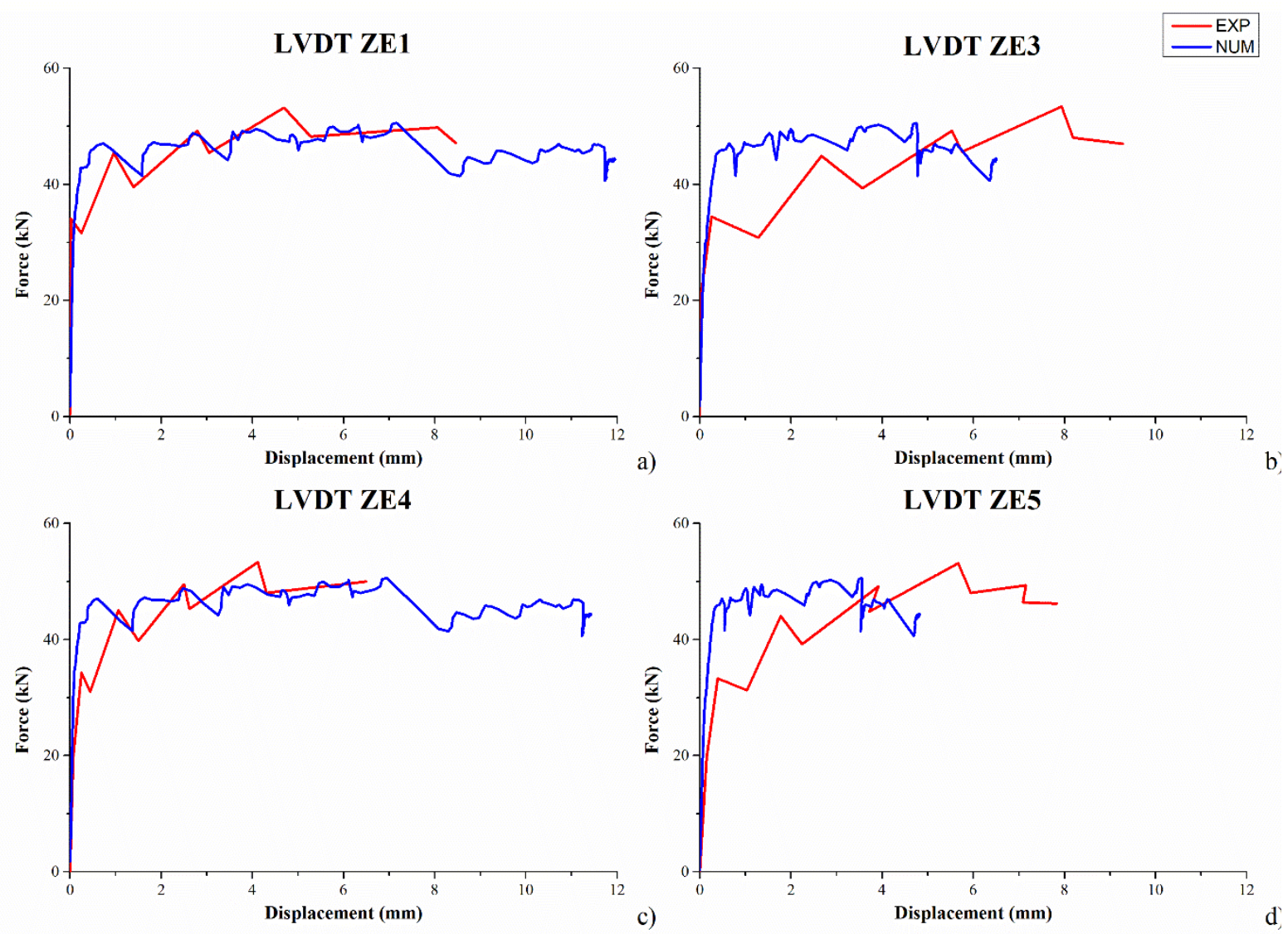

Figure 12. Comparison between experimental and numerical curves obtained testing the URM building: LVDTs ZE1 (-a)-ZE3 (-b)-ZE4 (-c)-ZE5 (-d).

305 Also, the model was adopted to accurately analyze the failure mechanism taking place in the unreinforced masonry building. The corresponding tensile damage maps obtained at representative time-steps are depicted in Figure 13. As expected, and confirmed by the experimental investigation, 

at the end of the first set of analysis.
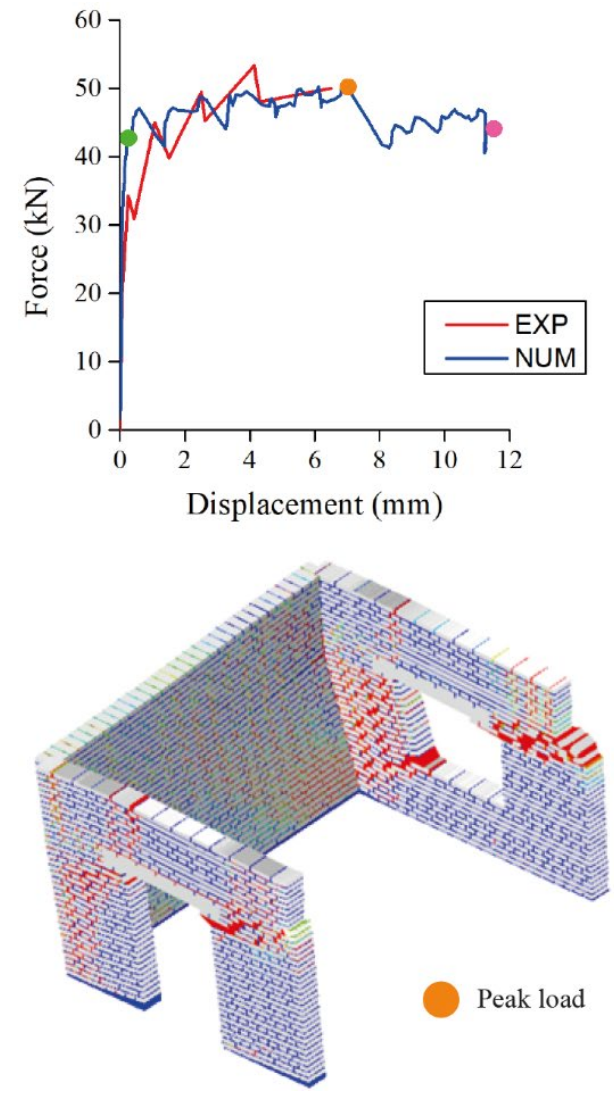

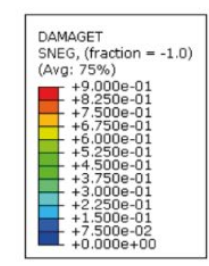

a)

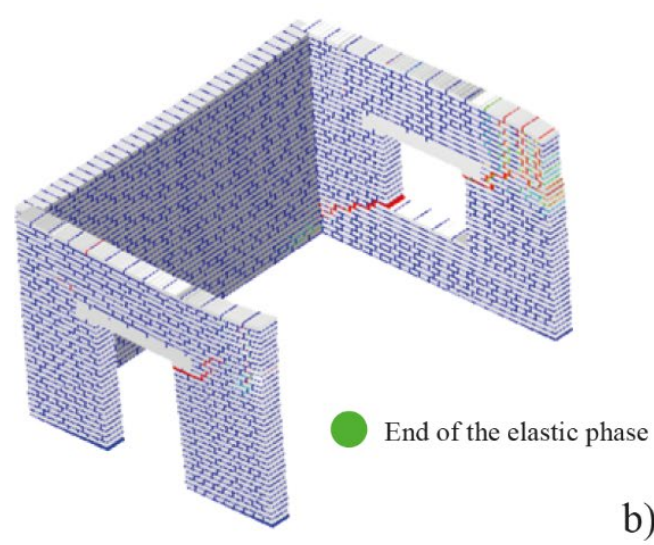

b)

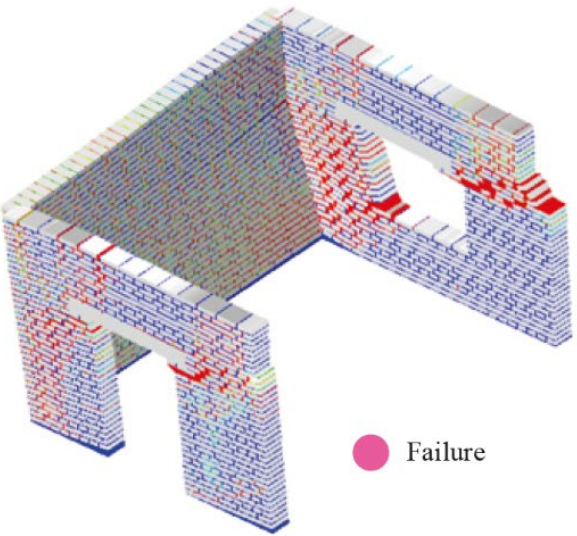

c)

Figure 13. Comparison between experimental and numerical curves obtained testing the URM building: LVDTs ZE4 (-a) and tensile damage maps obtained at representative time-steps: elastic (-b), peak (-c) and failure (-d).

310 Tensile damages formed on the lateral walls closed to the corners openings and propagated toward the

311 loading system following stepped paths. The tensile damage map obtained at peak load shows tensile

312 damages spreading widely in the lateral walls accompanied by the activation of torsional effects which

313 become more important as the damage spreads and the stiffness of the two walls decreases. Finally, the

314 activation of the front wall was also observed. This latter finding was marginally observed during the

315 experimental investigation, as the lab campaign involved pushing and pulling cycles which severely

316 damaged the areas connecting the masonry building to the loading system compromising the load

317 transmission. 

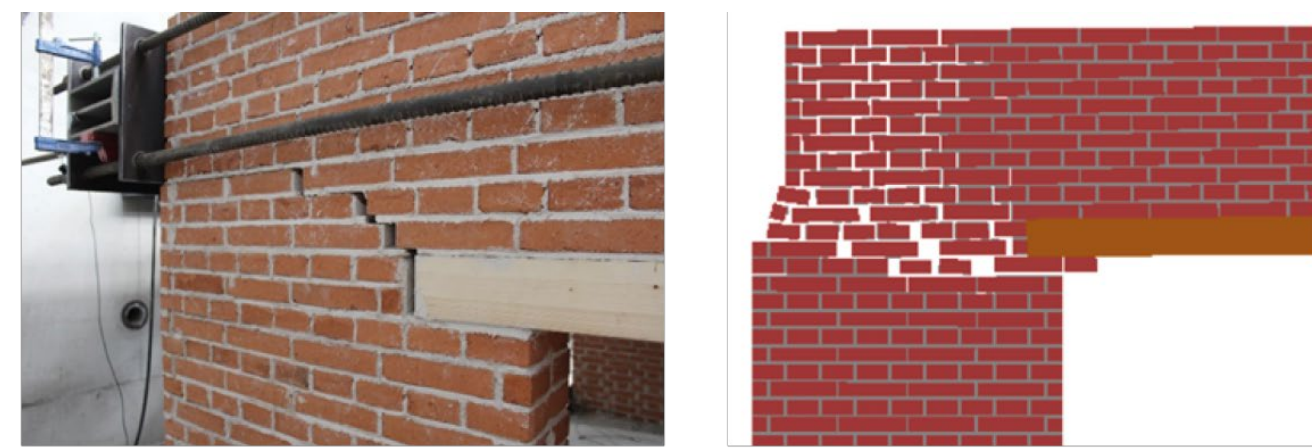

a)

b)
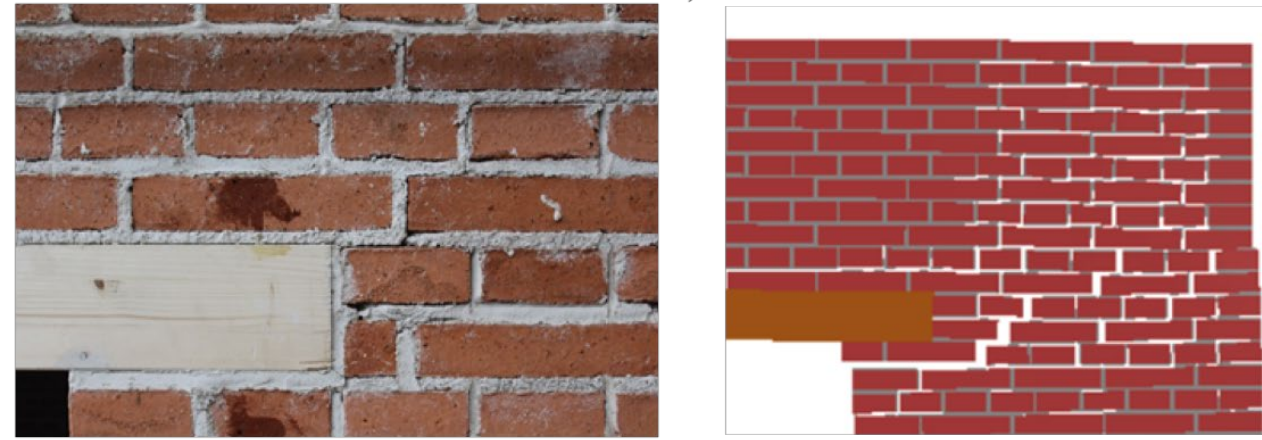

c)

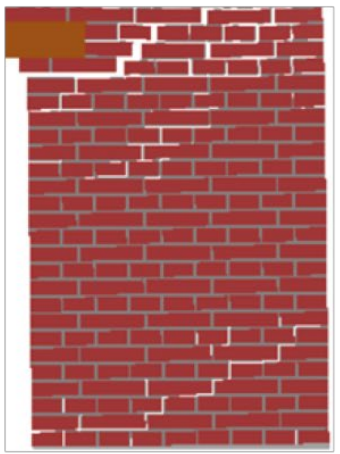

d)

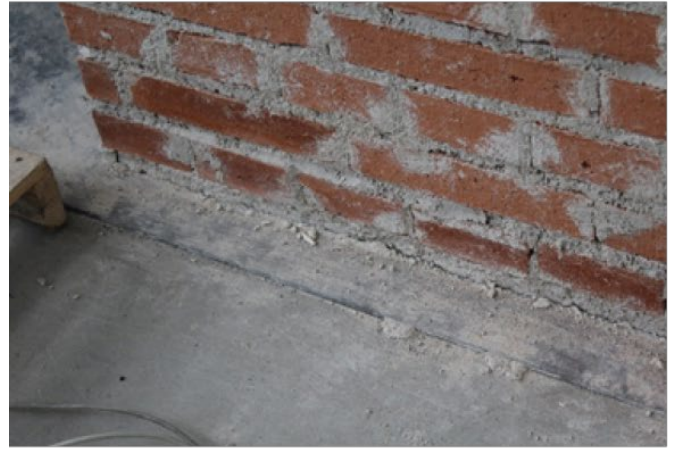

e)

Figure 14. Comparison between the damages observed in the real building and at the end of the FE analysis, considering: windowed panel (-a and -b), door panel (-c and -d) and detachment from reaction wall (-e and f).

318 A comparison between the damages observed at the end of the lab investigation on the masonry building and those obtained with the proposed FE model is depicted in Figure 14. Although the tension damages observed at the end of the simulations are more widespread on the wall support, the location and extent of the damage are strictly comparable to those observed at the end of the laboratory investigation.

\subsubsection{TRM reinforced masonry structure}

A similar FE model, considering a $10 \mathrm{~mm}$ thick TRM strengthening layer perfectly bonded to the masonry support was adopted to simulate the structural response of the masonry prototype severely damaged and repaired with TRM materials. As discussed in Section 3.1, the FE model was slightly 
modified in order to add the TRM strengthening material on the external masonry surface only. It is worth mentioning that the geometry, loading system, constraints and related boundary conditions, as well as the number of FE and DOF involved, were kept consistent with the as-built model. The numerical simulations were carried out considering that the TRM strengthening, injection and masonry repointing completely restored the original continuity of the masonry support. A preliminary evaluation of the accuracy provided using the proposed FE was performed by comparing the experimental envelope curves with the numerical ones. The comparison is depicted in Figure 15 considering LVDT $15-d)$, respectively.
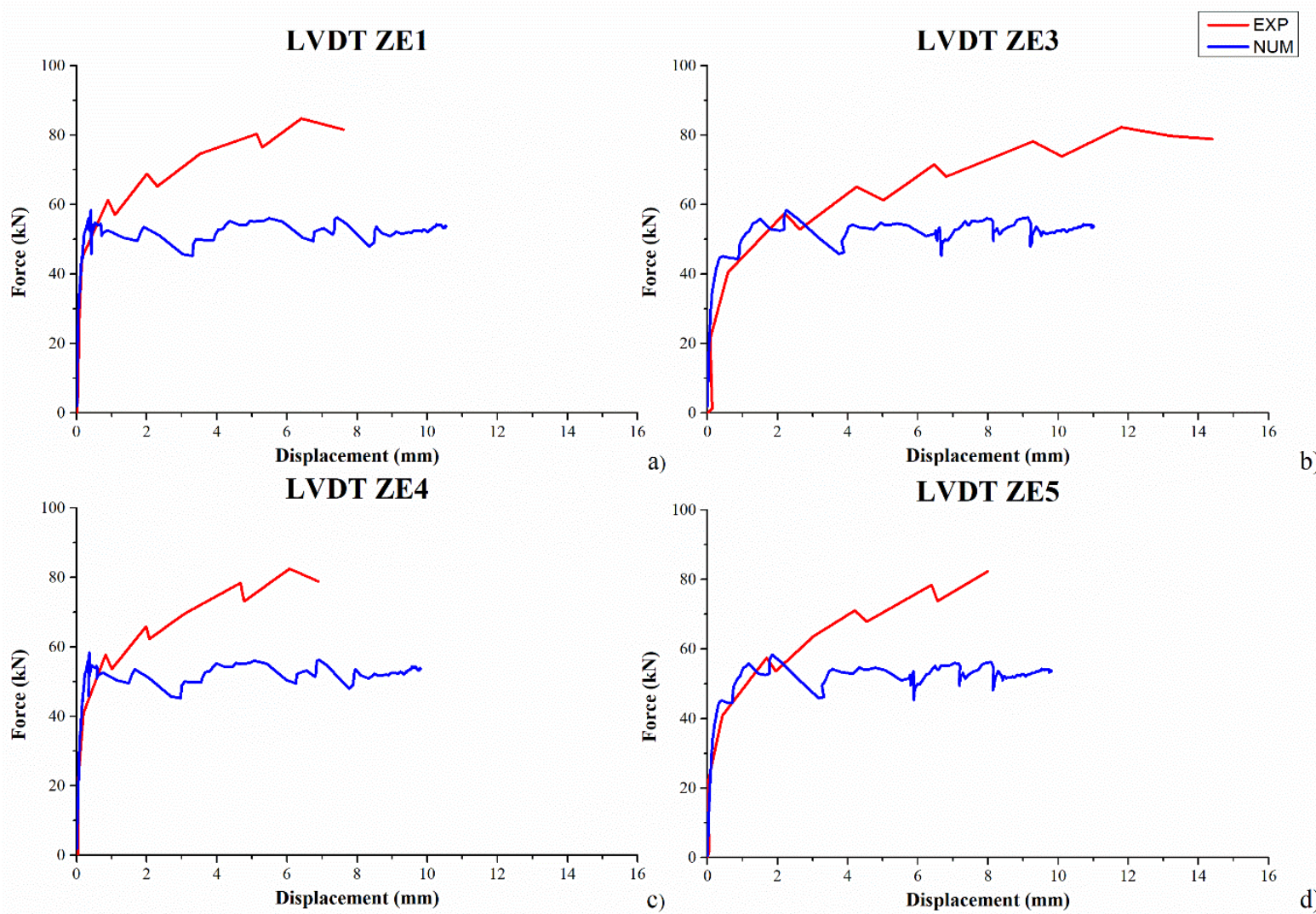

b)

Figure 15. Comparison between experimental and numerical curves obtained testing the TRM building: LVDTs ZE1 (-a)-ZE3 (-b)-ZE4 (-c)-ZE5 (-d).

335 Globally, the numerical capacity curves showed a good agreement with the experimental ones in terms of initial elastic phase and ductility. Slight differences were encountered in the peak load which was underestimated by the proposed FE model (approximately 29\% lower in the FE model). 


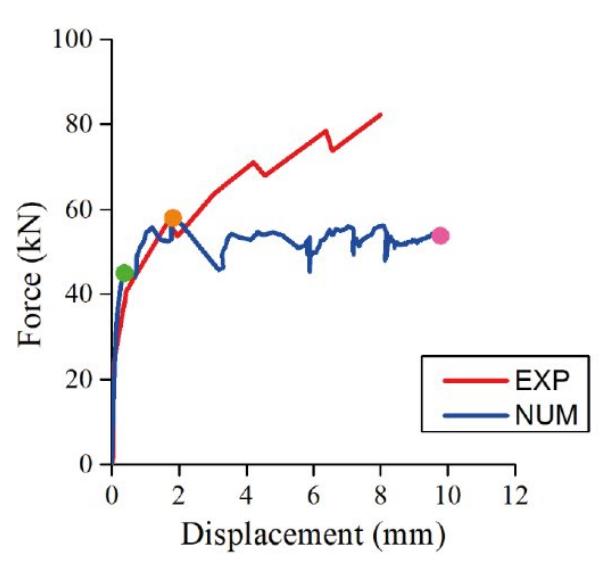

a)

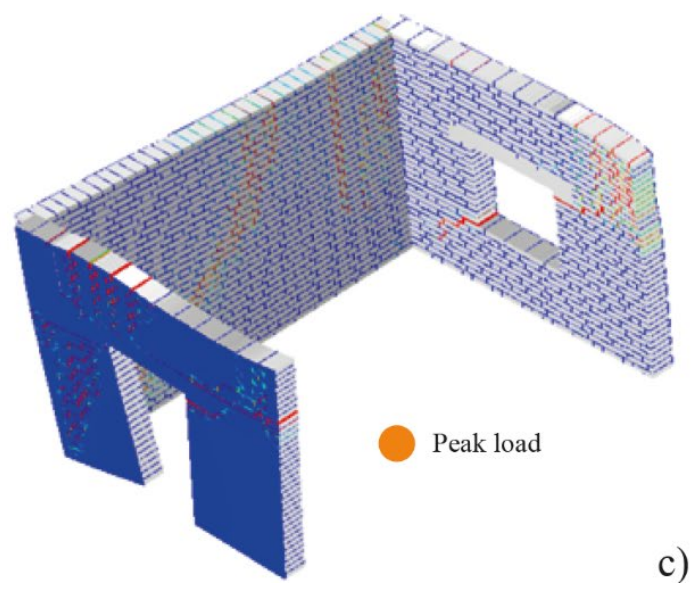

c)

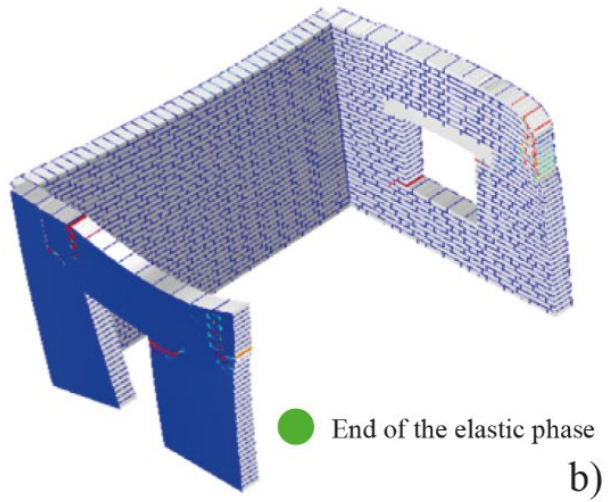

b)

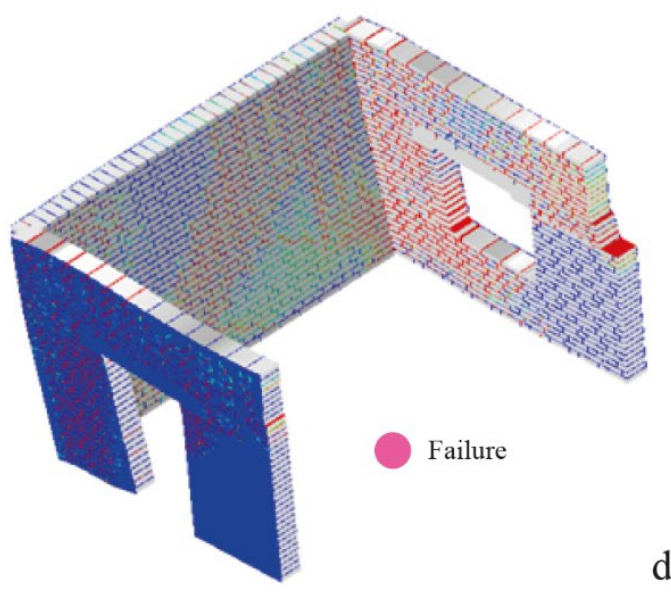

Figure 16. Comparison between experimental and numerical curves obtained testing the TRM building: LVDTs ZE5 (-a) and tensile damage maps obtained at representative time-steps: end of the elastic phase (-b), peak load (-c) and failure (-d).

To further evaluate the accuracy of the FE model, tensile damage maps were extracted at representative time-steps during the simulation (i.e., end of the elastic phase, peak load, and end of the simulation). Tensile damage maps ( $\mathrm{dt}$ varies from 0 to 0.9 ) are provided in Figure 16 together with a detail of the time-steps used to extract the crack patterns (Figure 16-a). Conversely to the unreinforced masonry building, the TRM strengthened one showed different crack patterns depending on whether the external (TRM strengthened) or internal surface is observed. The internal surface gives some insight into the level of damages on the masonry support, while the external one allows evaluating the performance of the TRM in terms of its failure modes (i.e., detachment from the support or sliding of the glass textile from the mortar matrix). In agreement with experimental evidence, more tensile damages spread over the masonry support at the end of the second lab investigation with cracks that reopened in correspondence of the repaired areas. However, the cracks were narrow and difficult to distinguish based on simple visual observations. In this regard, the FE model resulted particularly useful 
in estimating the areas where damages spread and the damage extent. Slight differences were also observed in terms of tensile damage on the TRM reinforcement layer, which suffered, according to the FE model, much greater tensile damage than in the laboratory investigation. A more detailed comparison between the damages experienced at the end of the second lab investigation and the FE simulation is provided in Figure 17.

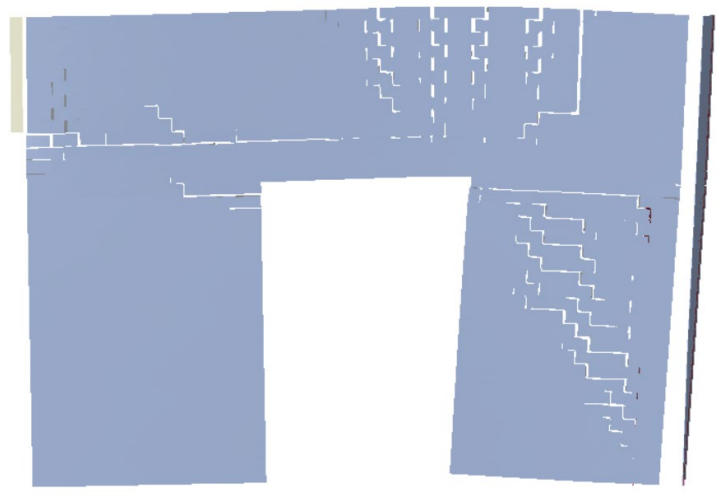

$-\mathrm{a}$

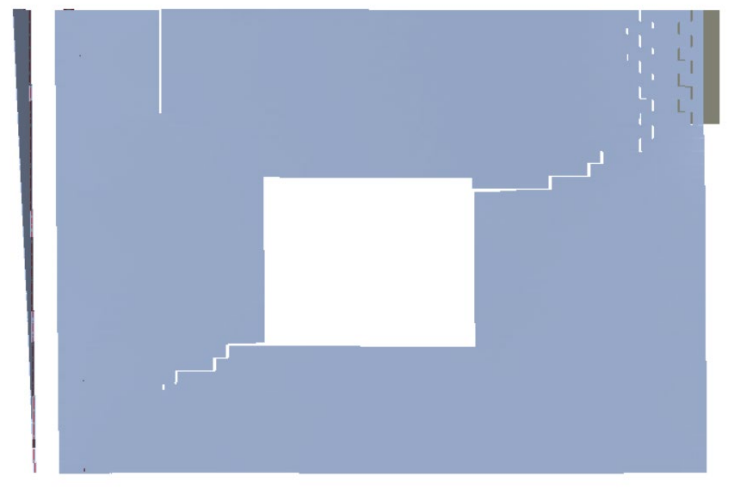

$-\mathrm{c}$

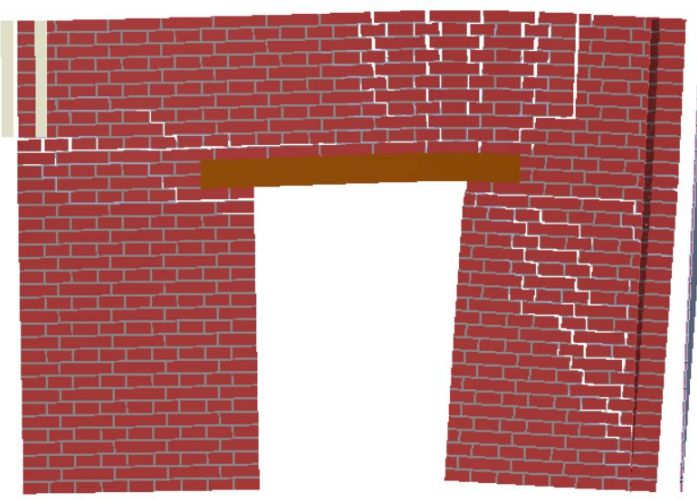

$-\mathrm{b}$

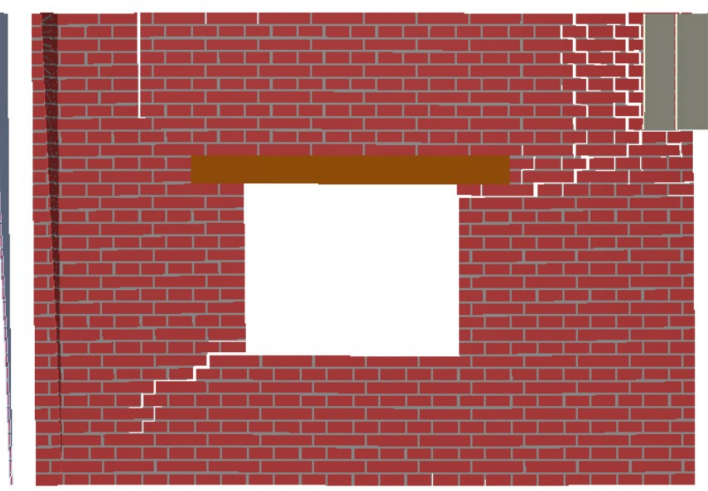

$-\mathrm{d}$

Figure 17. Damages observed at the peak of the FE analysis on the TRM reinforced structure, considering door's wall external (-a) and internal (-b) view, and the windowed wall internal (-c) and external (-d) view

As in the URM model, the tensile damage observed in the TRM strengthened one, is more widespread than in the experiment. However also in this model is possible to identify cracks showed by the building in correspondence to the up-door corners (Figure 17a-b and Figure 5c-d). The widespread damage in the model can be linked to the lack of pulling cycles but also to the micro-crack that probably developed on the walls behind the TRM. 
This work proposes an advanced nonlinear mechanical numerical micro-model developed using the software ABAQUS/Explicit to evaluate the evolution of damage following pseudo-dynamic tests on a damaged masonry structure unreinforced and reinforced with TRM material. The process first involved the calibration of some of the constituent materials' mechanical properties using modal analysis, followed by the study of the unreinforced and TRM reinforced building's structural response using an explicit integration scheme. From the analysis of the results the following conclusions can be drawn:

- The model represents a good compromise between computational efficiency and accuracy

\section{Data Availability Statement}




\section{Acknowledgements}

The authors would like to express their gratitude to the Spanish Ministry of Economy, Industry and Competitiveness for the funding provided (BIA 2014-59036-R-AR), and also to the Grupo Mapei and Grupo Puma for their invaluable assistance during the experimental tests.

\section{References}

Acito, M., Bocciarelli, M., Chesi, C., and Milani, G. (2014). "Collapse of the clock tower in Finale Emilia after the May 2012 Emilia Romagna earthquake sequence: Numerical insight.” Engineering Structures, 72, 70-91.

American Concrete Institute. (2013). “ACI 549-Guide to Design and Construction of Externally Bonded FabricReinforced Cementitious Matrix (FRCM) Systems for Repair and Strengthening Concrete and Masonry Structures.” Farmington Hills, U.S.A.

ARTeMIS Modal. (2018). "Structural Vibration Solutions A/S."

Babatunde, S. A. (2017). "Review of strengthening techniques for masonry using fiber reinforced polymers." Composite Structures, 161, 246-255.

Barducci, S., Alecci, V., De Stefano, M., Misseri, G., Rovero, L., and Stipo, G. (2020). "Experimental and Analytical Investigations on Bond Behavior of Basalt-FRCM Systems." Journal of Composites for Construction, 24(1), 04019055.

Bertolesi, E., Buitrago, M., Giordano, E., Calderón, P. A., Moragues, J. J., Clementi, F., and Adam, J. M. (2020). "Effectiveness of textile reinforced mortar (TRM) materials in preventing seismicinduced damage in a U-shaped masonry structure submitted to pseudo-dynamic excitations." Construction and Building Materials, 248, 118532.

Bertolesi, E., Milani, G., Carozzi, F. G., and Poggi, C. (2018). "Ancient masonry arches and vaults strengthened with TRM, SRG and FRP composites: Numerical analyses." Composite Structures, Elsevier, 187(October 2017), 385-402.

Betti, M., Facchini, L., and Biagini, P. (2015). "Damage detection on a three-storey steel frame using artificial neural networks and genetic algorithms." Meccanica, 50(3), 875-886. 
Bhattacharya, S., Nayak, S., and Dutta, S. C. (2014). "A critical review of retrofitting methods for unreinforced masonry structures." International Journal of Disaster Risk Reduction, 7, 51-67.

Bru, D., Ivorra, S., Buitrago, M., Bertolesi, E., Buitargo, M., and Bertolesi, E. (2019). "Oma identification on a scaled masonry building pre and post reinforced with TRM." 8th IOMAC, Copenhagen, $1-8$.

Caggegi, C., Carozzi, F. G., De Santis, S., Fabbrocino, F., Focacci, F., Hojdys, Ł., Lanoye, E., and Zuccarino, L. (2017). "Experimental analysis on tensile and bond properties of PBO and aramid fabric reinforced cementitious matrix for strengthening masonry structures." Composites Part B: Engineering, 127, 175-195.

de Carvalho Bello, C. B., Cecchi, A., Meroi, E., and Oliveira, D. V. (2017). "Experimental and Numerical Investigations on the Behaviour of Masonry Walls Reinforced with an Innovative Sisal FRCM System.” Key Engineering Materials, 747, 190-195.

Clementi, F., Ferrante, A., Giordano, E., Dubois, F., and Lenci, S. (2020). "Damage assessment of ancient masonry churches stroked by the Central Italy earthquakes of 2016 by the non-smooth contact dynamics method." Bulletin of Earthquake Engineering, 18(2), 455-486.

Consiglio Superiore dei Lavori Pubblici. (2018). "Linea Guida per la identificazione, la qualificazione ed il controllo di accettazione di compositi fibrorinforzati a matrice inorganica (FRCM) da utilizzarsi per il consolidamento strutturale di costruzioni esistenti (In Italian).”

Donnini, J., Corinaldesi, V., and Nanni, A. (2016). "Mechanical properties of FRCM using carbon fabrics with different coating treatments." Composites Part B: Engineering, 88, 220-228.

de Felice, G., D’Antino, T., De Santis, S., Meriggi, P., and Roscini, F. (2020). “Lessons Learned on the Tensile and Bond Behavior of Fabric Reinforced Cementitious Matrix (FRCM) Composites." Frontiers in Built Environment, 6.

Garofano, A., Ceroni, F., and Pecce, M. (2016). "Modelling of the in-plane behaviour of masonry walls strengthened with polymeric grids embedded in cementitious mortar layers." Composites Part B: Engineering, 85, 243-258.

Ghiassi, B. (2020). "Mechanics and durability of lime-based textile reinforced mortars." RILEM 
Giuffré, A. (1996). “A Mechanical Model for Statics and Dynamics of Historical Masonry Buildings.” Protection of the Architectural Heritage Against Earthquakes, Springer Vienna, Vienna, 71-152.

Grande, E., Imbimbo, M., and Sacco, E. (2018). "Numerical investigation on the bond behavior of FRCM strengthening systems.” Composites Part B: Engineering, Elsevier, 145(October 2017), $240-251$.

Harajli, M., ElKhatib, H., and San-Jose, J. T. (2010). "Static and Cyclic Out-of-Plane Response of Masonry Walls Strengthened Using Textile-Mortar System." Journal of Materials in Civil Engineering, 22(11), 1171-1180.

Hollaway, L. C. (2010). "A review of the present and future utilisation of FRP composites in the civil infrastructure with reference to their important in-service properties." Construction and Building Materials, 24(12), 2419-2445.

ICOMOS. (1964). "International charter for the conservation and restoration of monuments and sites (the Venice charter 1964)." International Council on Monuments and Sites (ICOMOS), Second International Congress of Architects and Technicians of Historic Buildings.

Ivorra, S., Torres, B., Baeza, F. J., and Bru, D. (2021). "In-plane shear cyclic behavior of windowed masonry walls reinforced with textile reinforced mortars." Engineering Structures, 226, 111343.

Masciotta, M. G., Ramos, L. F., Lourenço, P. B., and Vasta, M. (2014). "Structural monitoring and damage identification on a masonry chimney by a spectral-based identification technique." Proceedings of the International Conference on Structural Dynamic , EURODYN, 2014Janua(June), 211-218.

Mendes, N., Lourenço, P. B., Besca, M., Trufelli, E., and Barontini, A. (2016). "Diagnosis and Seismic Analysis of the Our Lady of Conception Church, Portugal." 199-219.

Milani, G., and Lourenço, P. B. (2013a). "Simple Homogenized Model for the Nonlinear Analysis of FRP-Strengthened Masonry Structures. I: Theory.” Journal of Engineering Mechanics, 139(1), $59-76$. 
Milani, G., and Lourenço, P. B. (2013b). "Simple Homogenized Model for the Nonlinear Analysis of FRP-Strengthened Masonry Structures. II: Structural Applications.” Journal of Engineering Mechanics, 139(1), 77-93.

Milani, G., and Valente, M. (2015). "Failure analysis of seven masonry churches severely damaged during the 2012 Emilia-Romagna (Italy) earthquake: Non-linear dynamic analyses vs conventional static approaches." Engineering Failure Analysis, 54, 13-56.

Monaco, A., Minafò, G., D’Anna, J., Oddo, M. C., and La Mendola, L. (2020). “Constitutive Numerical Model of FRCM Strips Under Traction." Frontiers in Built Environment, 6.

De Naeyer, A., Arroyo, S., and Blanco, J. (2000). "The Charter of Krakow 2000: principles for conservation and restoration of built heritage." Krakow, Polan.

Oliveira, D. V., Ghiassi, B., Reza Allahvirdizadeh, Wang, X., Mininno, G., and Silva, R. A. (2019). "Macromodeling approach for pushover analysis of textile-reinforced mortar-strengthened masonry.” Numerical Modeling of Masonry and Historical Structures, Elsevier, 745-778.

Papanicolaou, C. G., Triantafillou, T. C., Papathanasiou, M., and Karlos, K. (2008). “Textile reinforced mortar (TRM) versus FRP as strengthening material of URM walls: Out-of-plane cyclic loading." Materials and Structures/Materiaux et Constructions, 41(1), 143-157.

Penna, A., Morandi, P., Rota, M., Manzini, C. F., da Porto, F., and Magenes, G. (2014). "Performance of masonry buildings during the Emilia 2012 earthquake." Bulletin of Earthquake Engineering, 12(5), 2255-2273.

Ricci, E., Oliveira, D. V., Sacco, E., and Ghiassi, B. (2018). "Modelling of masonry arches strengthened at extrados with FRCM." 10th IMC, Milan.

Sadeghi, N. H., Oliveira, D. V, Silva, R. A., Mendes, N., Correia, M., and Azizi-bondarabadi, H. (2017). "Performance of adobe vaults strengthened with LC-TRM: an experimental approach." Protection of historical constructions, Lisbon, Portugal.

de Santis, S., de Felice, G., Di Noia, G. L., Meriggi, P., and Volpe, M. (2019). "Shake Table Tests on a Masonry Structure Retrofitted with Composite Reinforced Mortar.” Key Engineering Materials, $817,342-349$. 
SIMULA ABAQUS. (2014). “Theory manual, version 6.14.” Maastricht.

Di Tommaso, A., and Focacci, F. (2001). "Strengthening Historical Monuments with FRP: A Design Criteria Review." Composites in Construction, American Society of Civil Engineers, Reston, VA, $223-230$.

Torres, B., Ivorra, S., Javier Baeza, F., Estevan, L., and Varona, B. (2021). "Textile reinforced mortars (TRM) for repairing and retrofitting masonry walls subjected to in-plane cyclic loads. An experimental approach.” Engineering Structures, 231(4), 111742.

Venanzi, I., Kita, A., Cavalagli, N., Ierimonti, L., and Ubertini, F. (2019). "Continuous OMA for Damage Detection and Localization in the Sciri tower in Perugia, Italy." IOMAC - International Operational Modal Analysis Conference 2019At: Copenhagen, Denmark, Copenhagen, Denmark.

Vlachakis, G., Vlachaki, E., and Lourenço, P. B. (2020). "Learning from failure: Damage and failure of masonry structures, after the 2017 Lesvos earthquake (Greece).” Engineering Failure Analysis,

Wang, C., Sarhosis, V., and Nikitas, N. (2018). "Strengthening/Retrofitting Techniques on Unreinforced Masonry Structure/Element Subjected to Seismic Loads: A Literature Review.” The Open Construction and Building Technology Journal, 12(1), 251-268.

Wang, X., Ghiassi, B., Oliveira, D. V., and Lam, C. C. (2017). "Modelling the nonlinear behaviour of masonry walls strengthened with textile reinforced mortars." Engineering Structures, 134, 11-24. 